\title{
Efficacy of Cognitive Training Intervention with a Coaching Component on Attention and Response Control in Emerging
}

\section{Adults}

Thomas Craig Foster Jr

trfoster@mix.wvu.edu

Follow this and additional works at: https://researchrepository.wvu.edu/etd

Part of the Counseling Psychology Commons

\section{Recommended Citation}

Foster, Thomas Craig Jr, "Efficacy of Cognitive Training Intervention with a Coaching Component on Attention and Response Control in Emerging Adults" (2019). Graduate Theses, Dissertations, and Problem Reports. 4100.

https://researchrepository.wvu.edu/etd/4100

This Dissertation is protected by copyright and/or related rights. It has been brought to you by the The Research Repository @ WVU with permission from the rights-holder(s). You are free to use this Dissertation in any way that is permitted by the copyright and related rights legislation that applies to your use. For other uses you must obtain permission from the rights-holder(s) directly, unless additional rights are indicated by a Creative Commons license in the record and/ or on the work itself. This Dissertation has been accepted for inclusion in WVU Graduate Theses, Dissertations, and Problem Reports collection by an authorized administrator of The Research Repository @ WVU.

For more information, please contact researchrepository@mail.wvu.edu. 
Efficacy of Cognitive Training Intervention with a Coaching Component on Attention and Response Control in Emerging Adults

Thomas C. Foster, Jr., M.Ed.

\author{
Dissertation submitted \\ to the College of Education and Human Services \\ at West Virginia University \\ in partial fulfillment of the requirements for the degree of \\ Doctor of Philosophy in \\ Counseling Psychology
}

Monica Leppma, Ph.D., Chair

Jeffrey Daniels, Ph.D.

Daniel G. Long II, Ph.D.

Lisa F. Platt, Ph.D.

Christine Schimmel, Ed.D.

Department of Counseling, Rehabilitation Counseling, and Counseling Psychology

\title{
Morgantown, West Virginia
}

2019

Keywords: Cognitive training; attention; response control; cognitive coaching; academic achievement

Copyright 2019 Thomas C. Foster, Jr. 


\begin{abstract}
Efficacy of Cognitive Training Intervention with a Coaching Component on Attention and

Response Control in Emerging Adults

Thomas C. Foster, Jr.

Cognitive training, a nonpharmacological intervention for attention and learning-related difficulties, is a promising treatment option for emerging adults. The aim of this study was to explore the efficacy of a cognitive training program with a coaching component on measures of attention and response control in university students. Between 2014 and 2017, 39 students with reported attention concerns engaged in a cognitive training program over ten weeks (20 sessions) at a university counseling center. Differences in participants' attention and response control as measured by the IVA-2 Continuous Performance Test (CPT) were evaluated before and after the intervention. Demographic data, including clinician experience and school classification (e.g., freshman and sophomore), were also used to predict scores on the criterion measure. Findings showed that participants significantly improved on sustained attention, response control, and a combined measure of attention and response control after completing the program. Further, results from a regression analysis revealed that clinician experience and school classification did not significantly predict attention and response control outcomes. This dissertation study supports a growing body of research surrounding the efficacy of cognitive training, particularly those programs that incorporate a coaching element, in emerging adult populations.
\end{abstract}




\section{DEDICATION}

I would like to dedicate this dissertation to the people who have helped me immensely over the last 5 years. First, I dedicate this dissertation to my wife, Melissa. Without you, this would not have been possible. Your patience, encouragement, and love have given me the strength to carry on. I am always amazed with how much you were able to support me with your own work as a student and clinician. You have always been my favorite clinician.

I would also like to dedicate this work to my parents who have been my support system in all my academic endeavors. You have always encouraged me to "do my best" and have consistently nurtured my love of knowledge and pursuit of higher education. Further, I would like to dedicate this to my sisters, Lauren and Leah, and brother-in-law, Dave, who have been there for me through the highs and lows. I hope that in the coming years we will be able to see each other more often and live closer together.

Lastly, I would like to dedicate this dissertation to my extended family, the Nobles. I appreciate all the things you have done for us. You all have adopted me as a member of your family and provided guidance in many ways. Thank you. 


\section{ACKNOWLEDGEMENTS}

I would like to thank my dissertation chair, Dr. Monica Leppma, and my committee members for your guidance and assistance during this process. Your ideas and feedback have helped immensely in making this the best dissertation it could be. To Dan, thank you for your clinical guidance during my two years in the MindFit clinic. Without your encouragement, mentorship, and enthusiasm, this study would not have been possible. To my clinical supervisors, thank you for your support during graduate school, you have helped me grow as a person and become a clinician who cares deeply for my clients. To the Counseling Psychology faculty, thank you for helping me think outside of the box and for pushing me beyond my limits. Your words have echoed in my mind as I continue to grow as a psychologist. To my cohort members, I appreciate the support you all have provided, I'll always remember the fun times we had together! Finally, thank you to Chelsea and Samantha for providing feedback along the way. 


\section{TABLE OF CONTENTS}

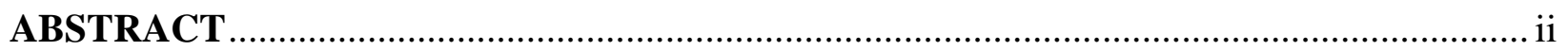

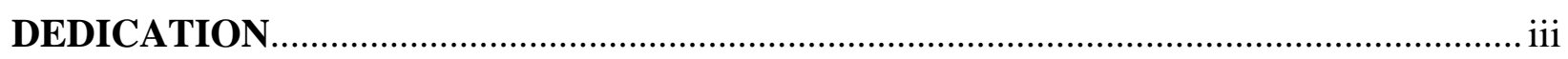

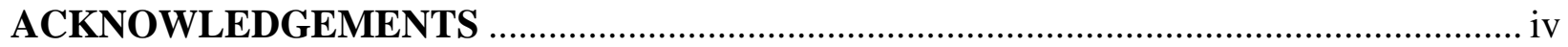

CHAPTER 1: INTRODUCTION AND LITERATURE REVIEW ….................................... 1

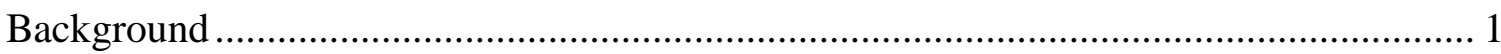

Cognitive Training as a Nonpharmacological Intervention............................................... 3

Cognitive training models .................................................................................... 4

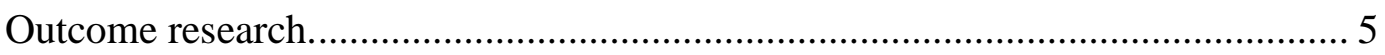

Cognitive training with a coaching component ..................................................... 10

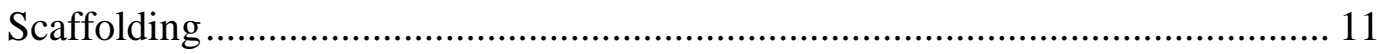

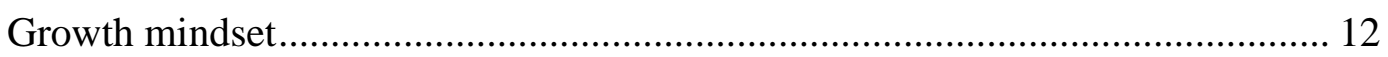

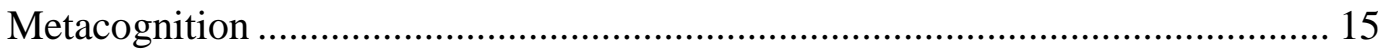

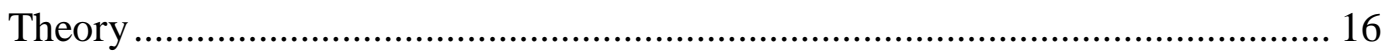

Cognitive Training in College Populations...................................................................... 18

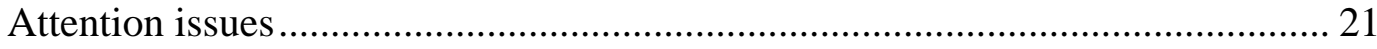

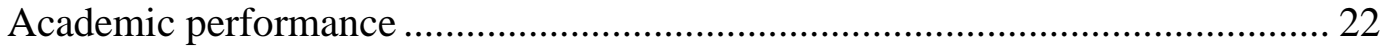

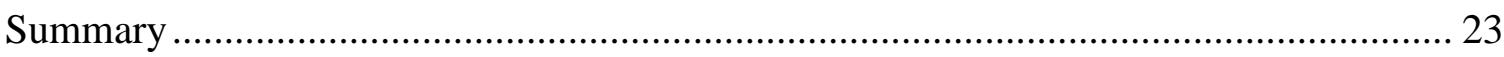

Research Questions and Hypotheses .............................................................................. 24

CHAPTER 2: RESEARCH DESIGN AND METHODOLOGY …………......................... 27

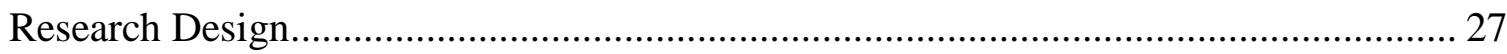

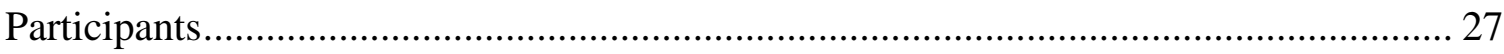

School Classification and Clinician Experience ……………………………………... 28

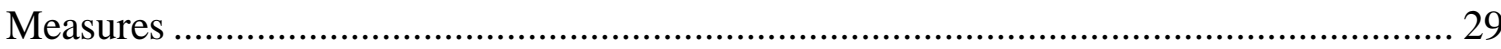

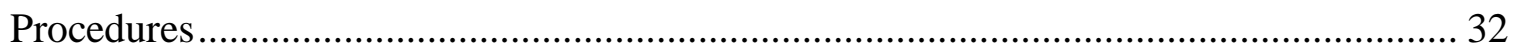

Cognitive Training Intervention with Coaching ................................................. 34

Sampling ................................................................................................ 35

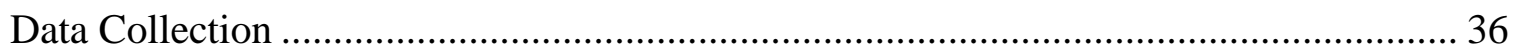

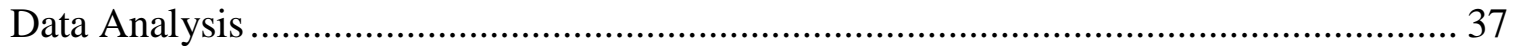

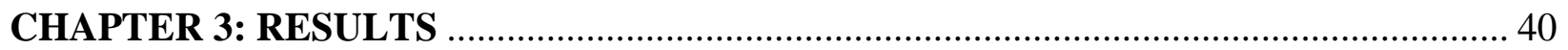

Coding and Scoring ................................................................................................. 40 


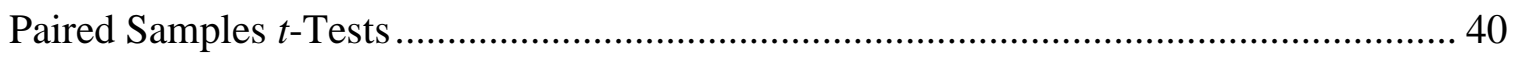

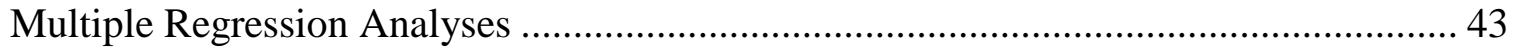

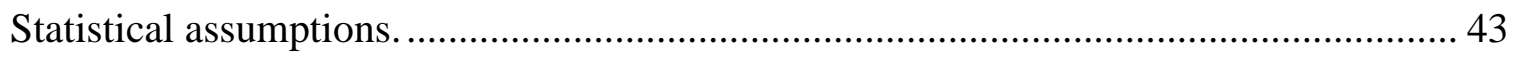

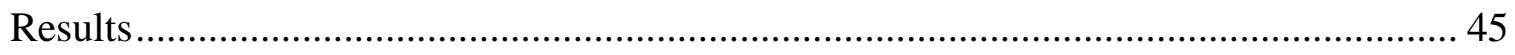

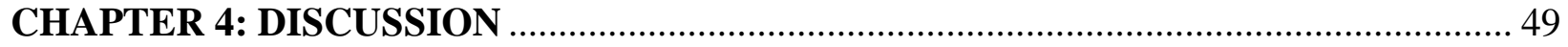

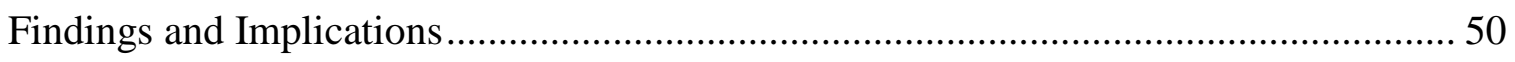

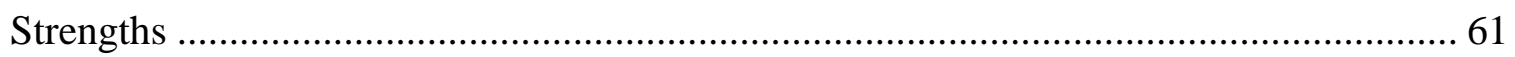

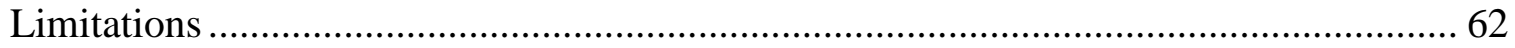

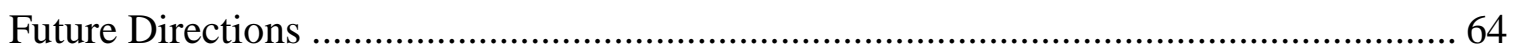

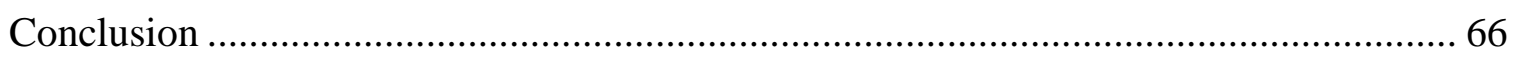

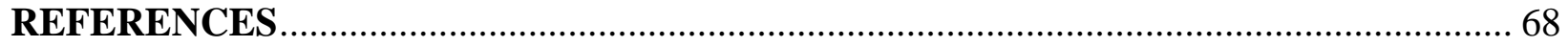

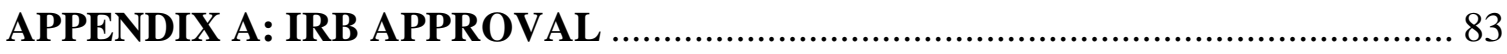

APPENDIX B: STUDENT DEMOGRAPHIC SURVEY (SDS) .............................. 85

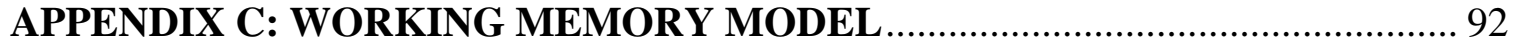

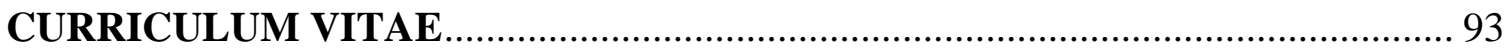




\section{CHAPTER 1: INTRODUCTION AND LITERATURE REVIEW}

Cognitive training is a nonpharmacological treatment for attention-deficit hyperactivity disorder (ADHD) and other learning-related difficulties. A growing body of literature indicates that cognitive training programs can improve a variety of cognitive processes in a range of psychological concerns and populations (e.g., Beck, Hanson, Puffenberger, Benninger, \& Benninger, 2010; Borella, Carretti, Riboldi, \& De Beni, 2010; Holmes et al., 2010). These programs, particularly those with a coaching element, offer considerable promise on college campuses where the potential for stimulant misuse is high (e.g., DuPaul, Weyandt, O’Dell, \& Varejao, 2009; Parker, Wales, Chalhoub, \& Harpin, 2013), though additional research is needed. This dissertation study evaluated the efficacy of a cognitive training program with a coaching component by examining functional differences in attention and response control before and after receiving the intervention. Further, this study explored how various demographic variables such as the experience of the clinician and academic classification (e.g., underclassmen, upperclassmen, and graduate students) could contribute to changes in treatment outcome. In this study, I sought to broaden the knowledgebase on cognitive training and contribute to growing discussions about the significant role of nonpharmacological interventions in the treatment of specific disorders ( $\mathrm{Li}$ et al., 2011). The remainder of this chapter is devoted to providing an overview of the relevant literature and summarizing the research questions and hypotheses.

\section{Background}

Since attention is multifaceted, it is a difficult term to operationalize and thus, cannot be reduced to a single definition or location in the brain (Tanji \& Hoshi, 2008). The complexity of this construct poses a roadblock for clinicians in the accurate assessment and diagnosis of 
clinically elevated attention difficulties, especially for clients with subclinical symptoms (Norén Selinus et al., 2013). While there is no uniform definition of attention, there is consensus in the scientific community that attention involves a cognitive process in which pertinent information is selected from our senses (Turgut, Yurttaş \& Tubbs, 2018). Several researchers have proposed theories of attention to better understand its etiology. For example, previous literature has described attention as both a bottom-up and a top-down process (Katsuki \& Constantinidis, 2014).

While external stimuli drive attention in bottom-up processing, internal factors such as goals, plans, and knowledge drive top-down processing (Peelen, Heslenfeld \& Theeuwes, 2004). Bottom-up processing, also known as exogenous attention, is stimulus-driven (Peelen et al., 2004). For example, an abrupt loud noise can draw attention in a pre-conscious manner. Bottom-up processing is thought to involve both the temporal and parietal lobes of the brain and the brainstem. Top-down processing, or endogenous attention, is categorized as attention that is under the control of the person (Peelen et al., 2004). Top-down processing is especially relevant in cognitive training. Top-down modulation, which is based on endogenous factors, allows the brain to direct attention to relevant stimuli and ignore distractions. The brain does this by improving activity in sensory areas for items that are applicable to the task and subduing activity for items that are less relevant (Peelen et al., 2004). Gazzaley and D’Esposito (2007) showed that top-down modulation of sensory processing occurs when long-range inputs are received from the prefrontal and parietal cortices. Top-down modulation parallels the brain's process of prioritizing information during working memory tasks (Curtis \& D’Esposito, 2003).

On the other hand, exogenous factors, which serve as the foundation for bottom-up processing, refers to the process of the mind to be captured by stimuli beyond what is presented 
in the normal visual field for the individual. Consequently, it is difficult for individuals to ignore exogenous cues but are wired to ignore endogenous cues. Thus, exogenous cues have greater effects than endogenous cues. As a result, a person's expectations about cue validity and predictive value affect endogenous attention to a greater degree than exogenous attention. Considering the properties of both endogenous and exogenous attention, endogenous attention emerges as the primary focus of cognitive training. The connection between endogenous attention and cognitive training suggests that if cues can be ignored, then they can also be learned, trained, and enhanced through specialized training.

\section{Cognitive Training as a Nonpharmacological Intervention}

The foundations of cognitive training can be traced back to Cajal's (1894) neuron doctrine. According to Cajal (1894), the human brain is malleable. He likened the brain to a garden that can be cultivated and grown. He believed that humans have the capacity to increase their cognitive capabilities at the biological and neural levels (DeFelipe, 2006). Today, it is widely accepted that the brain is a dynamic organ that adapts across the lifespan (Kramer et al., 2004; Markham \& Greenough, 2004). Similarly, cognitive training rests on the idea that cognitive abilities can be preserved and improved upon through brain exercises. Researchers have coined the ability to improve cognitive functioning as cognitive plasticity (Dweck, 2006). Willis and Shaie (2009) defined cognitive plasticity as, "an individual's latent cognitive potential under specific contextual conditions" (p. 375). This definition expanded on earlier research by suggesting that plasticity involves a person's capacity to develop greater cognitive skills (Jones et al., 2006; Mercado, 2008). 
Cognitive training models. Cognitive training offers promise given the limited efficacy of pharmacological interventions in holistically treating cognitive deficits (Parker et al., 2013). However, additional studies are necessary to understand the mechanisms underlying cognitive training, predictors of response, real-world applicability, and approaches to dissemination in practice settings. In practice, cognitive training can be applied in different ways. Hertzog, Kramer, Wilson, and Linderberger (2008) defined cognitive training as a set of repetitive exercises and tasks that seek to improve either one singular aspect of cognitive functioning such as memory, or a combination of cognitive abilities such as memory, attention, and executive functioning. This intervention can be delivered through a variety of formats including electronically or in person (Hertzog et al., 2008). Unlike other pharmacological and nonpharmacological modalities, a formal diagnosis is not necessary to engage in cognitive training. Thus, cognitive training is a highly appealing alternative to other treatments, particularly for individuals who cannot afford extensive psychological testing to receive a formal diagnosis.

Most cognitive training programs are conducted through computer-based exercises. For example, the facilitative intervention training (FIT) model is designed to strengthen the execution of one or more executive functions or attentional processes (Rapport, Orban, Kofler, \& Friedman, 2013). This program involves repetitive training exercises, continuous practice on behalf of the trainee, and weekly feedback from a trained administrator over the phone. The FIT model can be conducted using several computer programs: CogMed; Study-Developed; Pay attention!; AixTent; TEAMS; and/or Captain’s Log (Rapport et al., 2013). These programs differ in their selection of training targets including short-term memory, attention, and a mixture of executive functions (Rapport et al., 2013). Training differences in these programs highlight a 
lack of consistency across cognitive training programs that have proved problematic in the outcome literature.

Outcome research. Prior to 2000, many in the cognitive training community were skeptical about the efficacy of cognitive training (Hambrick, 2014). Since then, over 200 empirical studies have been conducted yielding a wide spectrum of results surrounding the efficacy of cognitive training programs like the one examined in the current study (Hurley, 2013). While some critics believe that cognitive training is ineffective, the larger consensus is that cognitive training has significant and beneficial results (Grady, 2008). Past literature has assessed the effects of cognitive training through psychometric tests of executive functioning, continuous performance tests (CPT), and working memory tests (e.g., Jaeggi et al., 2008; MelbyLervåg \& Hulme, 2013). However, these studies have been limited in terms of scope and generalization, focusing largely on children and elderly individuals (Beck et al., 2010; Borella et al., 2010). To lower the risk of age-related dementia, for example, many clinical trials have focused on studying the efficacy of cognitive training programs among elderly individuals (Borella, et al., 2010). In addition, other cognitive training trials have focused on children struggling with unmet academic expectations and/or ADHD symptoms (Zokaei, Mackellar, Čepukaitytè, Patai, \& Nobre, 2016). Recent research has combined cognitive training methods with functional imaging to evaluate changes in the brain during and after cognitive training. Cognitive science research has provided evidence that parts of the brain structure are malleable at a synaptic level throughout an individual's life, as first hypothesized in Cajal's (1984) neuron doctrine (DeFelipe, 2006). Cognitive training programs are, in part, a direct application of these findings. 
Considering the criticism surrounding cognitive training in the scientific community, studies that evaluate the efficacy of cognitive training programs, like the current study, are especially timely and important. There is a deep divide in the cognitive training community about how to make sense of outcome research conducted over the last 15 years (Melby Lervåg \& Hulme, 2013). Critics of cognitive training assert that many of the outcome experiments yield narrow improvements, usually related to the task being trained, which do not generalize to other abilities such as reading, mathematics or other measures of executive functioning (Jaeggi et al., 2008). While some studies on cognitive training demonstrate improvement in cognitive functioning (Au, Buschkuehl, Duncan, \& Jaeggi, 2016; Harrison et al., 2013; Jaeggi et al., 2008; Shipstead, Redick, \& Engle, 2013), others indicate that cognitive training is no more effective than a placebo (Kable et al., 2017).

Some results indicate a moderate to large effect size of cognitive training and specific cognitive domains, known as near transfer effects (Knafo \& Venero, 2014). Existing research has suggested that working memory may be weaker among individuals with attention issues (McCabe, Roediger, McDaniel, Balota, \& Hambrick, 2010). However, Melby-Lervåg and Hulme (2013) found short-term improvements in working memory, particularly in verbal working memory, among individuals engaged in cognitive training. That said, there is still a gap in knowledge concerning the sustainability of these gains in visuospatial and verbal working memory skills and improvement in areas outside the trained domain(s), or far transfer effects (Melby-Lervåg \& Hulme, 2013). Compared to near transfer effects, studies on far transfer effects remain far less conclusive, resulting in scientific debate. Due to inconsistencies in methodology, researchers have found conflicting results, demonstrating both support and a lack 
of evidence supporting the impact of cognitive training on far transfer effects such as fluid intelligence (Shipstead et al., 2013).

Critics have also pointed to other studies that have produced conflicting results. For example, Jaeggi et al. (2008) found that a cognitive training program resulted in significant improvements in on-task behavior. However, Chooi and Thompson (2012) found conflicting results in their attempt to replicate this study. Chooi and Thompson (2012) conducted the study with tighter controls and seventeen cognitive-skills tests. Findings from the study indicated no significant improvement in the examined areas of intelligence. The research team argued that the conflicting findings were due to methodological problems in the Jaeggi et al. (2008) study including weak controls and over reliance on a single outcome measure for determining cognitive improvement.

More recently, a group of researchers found that working memory training did not improve intelligence in young adults (Clark, Lawlor-Savage, \& Goghari, 2017). Although promises of improved intelligence may be outside the scope of cognitive training exercises, working memory training may still improve other localized functioning like working memory capacity and the capacity of the focus of attention (Chooi \& Thompson, 2012). It is possible that mixed results in the outcome research are attributed to insufficient evaluation techniques which Noack, Lovden, and Schmiedeck (2014) identified as a long-standing problem found in this area of research.

Another criticism of existing outcome literature is the disconnect between the dependent variables identified and the scope of the cognitive task being trained. For instance, many studies have measured intelligence as a dependent measure with an intervention of a dual n-back task (Melby-Lervåg \& Hulme, 2013). Studies have shown that n-back training, which affects 
working memory (WM), predicts performance in several cognitive tasks extending from attentional tasks (Fukuda \& Vogel, 2009) to tasks encompassing more multifaceted abilities, such as reading comprehension (Daneman \& Carpenter, 1980). Therefore, one could expect that training-related increases in WM efficiency are reflected as improvements in several other functions. However, the skills trained in an n-back task like short term memory (Kirchner, 1958) are but a sliver of the WM construct. The danger in associating a multi-dimensional dependent variable like intelligence with an intervention like the n-back task is that the researcher may inadvertently equate WM with overall intelligence. In the cognitive training field, there is a need for a comprehensive understanding of the characteristics of cognitive functions that could benefit from WM training.

Mixed results throughout the cognitive training literature have been further complicated by efforts to market cognitive training, known as "brain training," to consumers (Hurley, 2013). Developers of cognitive training software programs, such as Luminosity, have purported claims that such training can have significant transfer effects on learning and fluid intelligence among participants. Some companies have marketed these programs as a panacea for individuals at risk for Alzheimer's disease and Dementia (Zokaei et al., 2016) without empirically-rigorous testing. The marketing of these brain training products to vulnerable populations has been denounced by members of the cognitive training community (Holman \& deVillers-Sidani, 2014). In 2014, over 70 psychologists and neuroscientists at the Stanford Center on Longevity and The Max Planck Institute for Human Development drafted an open letter expressing their issues with these claims, citing a lack of compelling scientific evidence (Barbarito, 2016). Later, in an open response, 133 scientists responded that a "large and growing body" of evidence has shown that certain cognitive training methods have yielded improvement in cognitive functioning (Simons et al., 
2016, p. 121). These conflicting claims of efficacy have dominated the field in recent years. One of the primary aims of the current study was to help reconcile these differences and to explore how cognitive training gains might translate to real-world performance in emerging adults (Simons et al., 2016).

Researchers have demonstrated efforts to reconcile these mixed findings. For example, Melby-Lervåg and Hulme (2013) conducted a systematic meta-analytic review to address the variability of outcome results of working memory training. To be included in the review, studies had to either be randomized controlled trials or quasi-experiments without randomization. Further, each study had to include a treatment intervention with either a treated group or an untreated control group. In total, 23 studies with 30 group comparisons met these inclusion criteria out of the 227 studies that were initially examined. These studies included both clinical samples and samples of typically developing children and older adults. Results from MelbyLervåg and Hulme (2013) indicated that working memory training programs produced consistent short-term gains in working memory. However, there was no conclusive evidence of the generalization of working memory training to other abilities (i.e., word decoding, verbal and nonverbal ability, arithmetic, and inhibitory processes in attention). Melby-Lervåg and Hulme (2013) determined that memory training programs seem to produce short-term and narrow training effects but do not generalize to everyday tasks. However, other findings have been skeptical of both the clinical significance of working memory training programs and their usefulness as methods for enhancing cognitive functioning in children and healthy adults (Jaeggi et al., 2008; Stephenson \& Halpern, 2013). For instance, a meta-analysis conducted by Au et al. (2016) found that working memory training could have beneficial effects on cognitive functions such as fluid intelligence $(G f)$, following weeks of training and as measured by laboratory tests. 
Cognitive training with a coaching component. Coaching in cognitive training is the process in which the clinician provides feedback to the participant to help them improve their performance while engaging in a cognitive training program. This type of cognitive training model is clinician-driven, as opposed to program-driven. In most cognitive training models, like the FIT model, feedback is provided over the phone on a weekly basis by a clinician. However, most of these programs involve electronic interface with a clinician in which the client is engaged in computer-generated exercises. Cogmed, one of the largest purveyors of cognitive training software, uses an adaptive strategy when training, adjusting task difficulty based on the individual's performance. Programs like Cogmed demand that the user actively maintain performance (Roche \& Johnson, 2014). Thus, the user's performance is the only source of information determining task difficulty. This program is not sophisticated enough to determine the motivational level or other external factors that could impact the user's performance.

As a first step in addressing this dilemma, this study examined the effects of a cognitive training program in which the clinician was present with the client during the entire intervention (Long, 2017). That is, the clinician took an active role in the cognitive training process. This cognitive training program involved a range of digital and physical tasks that sought to augment attention, memory, and other functions of cognitive performance. This is an innovative program unlike any other cognitive training program currently available and to the researcher's knowledge, no other studies have evaluated similar interventions.

The presence of the clinician with the client could offer several advantages over other forms of cognitive training that favor weekly feedback over the phone. For one, research has demonstrated that common factors in the psychotherapy relationship are associated with improved client outcomes regardless of the clinician's theoretical orientation (Wampold, 2015). 
Similarly, it is possible that cognitive programs that have a relational or coaching element could exhibit improved treatment outcomes. While cognitive training is not psychotherapy, the stimulus value of the clinician's presence during treatment has yet to be accounted for in the literature. There are several advantages of a coaching element in cognitive training as the clinician could help the client cultivate a growth mindset, metacognitive strategies, and response control. Further, the presence of the clinician provides the client with scaffolding instruction which is outlined in the next section and may help the participant further retain the skills they develop in the cognitive training program. Related to the current study, the researcher examined clinician experience as a variable of interest in treatment efficacy. In previous cognitive training studies using a coaching component, samples collected were that of patients with schizophrenia. The purpose of the studies was in the cognitive remediation of the patients to improve their cognitive functioning (Penadés et al., 2006; Wykes et al., 2003). Differences between these studies and the current study, most notably different populations sampled and broader transfer effects, limit the generalizability to this study of the coaching construct within cognitive training.

Scaffolding. The cognitive training intervention in this study differed from others found in the literature because the clinician can ensure that tasks are both challenging and achievable for the client, an idea known as scaffolding. Drawing upon Vygotsky's (1978) social development theory, this approach used the zone of proximal development to increase the cognitive capabilities of the client in terms of working memory and attention. In contrast to other cognitive training protocols in which the computer algorithm dictates advancement, the clinicians who facilitated the cognitive training program in this study used their clinical judgment to assess the client's progress and determine the pace of the programming. 
This cognitive training program implemented in this study used scaffolding techniques to tailor the program and associated tasks to the unique needs of each client. Scaffolding is a broad term that encompasses various instructional strategies in which learners are provided with greater support from the instructor when initially learning a new task. As the learner progresses, however, the instructor moves towards shifting greater responsibility and autonomy to the learner. In this treatment model, the client is given a task that is sufficiently challenging but does not overwhelm their current abilities which is monitored and adjusted by the clinician.

Scaffolding can be used to condense an individual's cognitive load from simple-to-complex sequencing and reduce inessential aspects of the program. In other words, the clinician relies on their clinical discretion to determine the pace and difficulty of the programming based on the client's needs and current skill level. For example, a client engaged in cognitive training may engage in a task by using compensatory strategies such as writing their thoughts on paper. However, as they progress in treatment, they may advance towards completing the task without the assistance of writing based on an assessment of their current abilities by the clinician (Paas, Renkl, \& Sweller, 2013).

Growth mindset. Dweck (2006) coined the terms fixed mindset and growth mindset to describe people's beliefs about learning and intelligence. Blackwell, Trzeniewski, and Dweck (2007) found that students who believed their intelligence could be developed (growth mindset) outperformed those students who believed their intelligence was static (fixed mindset) on the Citywide Achievement Test (CAT). Further, a growth mindset is not simply an increase in effort, but involves the perception that effort is associated with learning and improvement overall (Dweck, 2015). The cognitive training program that was evaluated in this study sought to promote a growth mindset by fostering a treatment plan in which the process of learning is 
valued over the outcome. In contrast to other cognitive training programs in which the clinician is not present with the client, the program in this study was tailored to the participant's individual learning style. In this setting, the clinician acted as a coach, helping the client to embrace imperfections and develop new learning tactics.

Based on previous literature, it is possible that a cognitive training program that fosters a growth mindset could afford several benefits to consumers. For one, previous studies have examined the connection between a growth mindset and academic achievement. Blackwell et al. (2007) followed 373 students across the challenging transition from elementary school to seventh grade. At the beginning of seventh grade, the researchers assessed the students' perceptions of learning and improvement, along with other motivation-relevant variables, and divided the sample according to those students with a fixed mindset and those with a growth mindset. Blackwell et al. (2007) monitored the students' math grades over the next two years. Students in both groups entered the seventh grade with equal prior math achievement, illustrating that the impact of a growth or fixed mindset does not typically emerge until students face challenges or setbacks such as a challenging math course. By the end of the first semester, there were significant differences in the math scores between students with a growth mindset and students with a fixed mindset. The researchers observed that the students' grades continued to diverge over the next two years. Students from the experimental group, which constituted those individuals who believed that intelligence is malleable, demonstrated higher grades than the control group.

Similarly, Grant and Dweck (2003) studied college students enrolled in a pre-med curriculum $(n=451)$. The researchers measured the students' achievement in an organic chemistry class which served as the curriculum's gateway course. To address issues in the 
achievement motivation literature, the researchers focused on the students' goals, including the extent to which they were oriented toward learning goals versus the extent to which they were concerned with validating their intelligence though academic performance. Results suggested that active learning goals predicted active coping, sustained motivation, and higher achievement in the presence of challenge. Likewise, among performance goals, ability-linked goals predicted withdrawal and poorer performance in the presence of challenge. Research has shown that learning goals and the need to validate intelligence are closely aligned with mindset. Students with a growth mindset tend to be more oriented toward learning goals, while students with a fixed mindset tend to be more oriented toward validating their intelligence through performancebased goals (Blackwell et al., 2007; Dweck \& Leggett, 1988; Hong, Chiu, Dweck, Lin, \& Wan, 1999).

In addition to academic achievement, studies have examined how a growth mindset can affect performance in tasks of general intelligence and working memory (Dweck, 2015), though less is known about these areas. Results from a recent study on working memory training showed a negative correlation between an improvement on the n-back training task and a growth mindset $(r=-.44, p=.051)$. In fact, participants who perceived intelligence as flexible demonstrated greater improvement in their n-back scores (Thompson et al., 2013). In a study with preschoolers, Diamond, Barnett, Thomas, and Munro (2007) showed that participants' executive control levels were substantially increased through a training regimen that increased the children's experiences with response inhibition tasks. Furthermore, Jaeggi, Buschkuehl, Jonides, and Perrig (2008) found that participants who were trained on a demanding working memory task scored significantly higher on an unrelated test of fluid intelligence which 
measured the participants' abilities to reason and solve new problems. Moreover, the longer the program, the more gains participants made as a result of the training.

Metacognition. The cognitive training intervention in this study incorporated the principles of metacognition. Metacognition refers to a person's beliefs about how they think (Fisher, 1998). More specifically, metacognition encompasses the processes of an individual to plan, monitor, and assess their performance and understanding (Hatano \& Inagaki, 1986). Metacognition has been used in a variety of clinical and applied settings and in 2000, the National Academy of Sciences published findings from decades of research on the subject (National Center for Education Statistics [NCES], 2017). Overall, the data suggested that there is a significant relationship between metacognition and greater ability to transfer learning to new contexts and tasks (NCES, 2017). This process occurs when an individual understands the limits of their knowledge and figures out how to expand those limits. Unlike other programs, the cognitive training intervention in the current study sought to increase metacognition through in vivo feedback provided to the client from the clinician.

Tanner (2012) suggested specific activities for improving the effectiveness of metacognitive practices. While these activities were initially created for academic teaching, they lend themselves well to cognitive training. First, students are asked to examine their current thinking and reflect on what they already know about the processes that could positively or negatively affect their performance. Next, individuals are given a task in which they must navigate confusing material. The instructor then asks participants to reflect on the most confusing aspect of the material in order to increase the students' awareness of their own thought processes. After reflecting on the "muddiest point, a retroactive post-assessment of conceptual change is facilitated" (Tanner, 2012). During this activity, students are given the opportunity to 
assess whether their thinking has changed over time. Tanner (2012) indicated that reflective journaling can help participants continue to monitor their thinking following the intervention. In this study, reflective journals were replaced by a conversation between the clinician and the client about what worked well and what needed to be improved for next time. In this regard, the clinician acts as a coach for the client. Results from this reflective dialogue are then reintegrated into the treatment plan.

Theory. In addition to constructs like growth mindset, metacognition, and the therapeutic alliance, this cognitive training protocol used a specific theory of working memory as a guide for training interventions. The Working Memory Model as proposed by Baddeley and Hitch (1974) served as a theoretical framework for the cognitive training program in the current study (see Appendix C). This model consists of three main sections, or slave systems, and a supervisory system. The supervisory system, named the central executive, is considered the most important because it manages the slave systems and is important in both the management and retrieval of information from long term memory (Baddeley \& Hitch, 1974). The cognitive processes are distributed from the central executive to one of three slave systems: the phonological loop, the visuo-spatial sketchpad, and the episodic buffer. It is at this granular level that clinicians in the present study worked with the participants in improving their working memory (Baddeley \& Hitch, 1974).

The phonological loop in the Working Memory Model contains the phonological store and the articulatory control system and is critical in learning new vocabulary, math problems, problem-solving and remembering instructions (Baddeley \& Hitch, 1974). The phonological store is also known as the inner ear and is linked with the perception of speech. In the phonological store, spoken words can be maintained for one to two seconds and sounds of 
speech are retained in the order they were heard (Baddeley \& Hitch, 1974). The function of the phonological store is to help retain information which would quickly diminish if a mechanism did not exist to refresh the information. The articulatory control process allows for the sub-vocal repetition of the items in the phonological store. In addition, the articulatory control process converts material that is written into phonological code so it can be entered into the phonological store (Baddeley \& Hitch, 1974).

Complementing the auditory components of the phonological loop, the visuo-spatial sketchpad oversees visual and spatial processing (Baddeley \& Hitch, 1974). Within the visuospatial sketchpad, the visual cache stores information related to visual forms and color. The inner scribe takes information from the visual cache and moves it from the visual cache to the central executive (Baddeley \& Hitch, 1974). Additionally, the inner scribe is responsible for spatial and movement information such as body movements. For instance, when an individual moves from one location to another, the visuo-spatial sketchpad is activated. Likewise, in the context of cognitive training, the visuo-spatial sketchpad stores the location of objects. Activities which engage direction and spatial abilities such as puzzles and mazes directly target the visuospatial sketchpad.

Lastly, the episodic buffer, not originally included in Baddeley's model, is a place where information is temporarily integrated from the slave systems and long-term memory. The addition of the episodic buffer provides an added link between working memory and long-term memory as the buffer transfers information to and from long-term store, yet it is controlled by the central executive (Baddeley \& Hitch, 1974). In training, the episodic buffer can be seen in the retrieval of strategies learned from previous sessions and the synthesis of this information with the immediate information gathered from the slave systems (Baddeley \& Hitch, 1974). 
Each of the three slave systems and the episodic buffer are assessed by the clinician whilst observing the participant engaged in a cognitive task. For each of the working memory components, a corresponding set of tasks on the computer program are assigned and given preference in their protocol if a deficit is observed. For instance, if a deficit in the visuo-spatial sketchpad is observed, the clinician would choose tasks from the Captain's Log Mindpower Builder database related to visual scanning identification and visual memory identification. Likewise, deficits in the phonological loop or store are remediated through tasks on the Captain's Log related to auditory pattern recognition, sequential memory patterns, and conceptual sequential patterns. A relative strength of the cognitive training protocol utilized in this study is that the clinician is making the determination about what tasks to use and when. The adaptability and flexibility of the clinician to make decisions about tasks and techniques (e.g., scaffolding) are the foundations of this protocol and are aimed to keep the client in the zone of proximal development, which has been shown as an effective tool in cognitive performance.

\section{Cognitive Training in College Populations}

This study assessed the efficacy of a cognitive training program among a sample of college students, many of whom were emerging adults. Emerging adulthood is a distinct developmental stage. During this stage, the prefrontal cortex, responsible for executive function and attention, continues to form and neural pathways are both pruned and strengthened (Johnson, Blum, \& Giedd, 2009). Arnett (2000) defined emerging adults as individuals between 18 and 25 years old who face the developmental task of becoming increasingly independent and autonomous. Approximately $60 \%$ of emerging adults go on to pursue higher education (Brock, 2010). Thus, research on this population is highly relevant to university administrators and practitioners because many college students are also emerging adults. 
As discussed, previous studies on the efficacy of cognitive training have primarily focused on elementary-aged students and older adults (Melby-Lervåg \& Hulme, 2013). While cognitive training research has largely overlooked emerging adults, a few studies in the field have attempted to examine this population. For example, Jairam (2014) evaluated how cognitive training can be used to increase academic self-efficacy. A total of fifty undergraduate students were randomly assigned into one of two equally sized groups. The control group completed a placebo computer-based training program, while the experimental group completed a Lumosity training regimen, a commercially available web-based cognitive training program. Training sessions consisted of four game-like exercises designed to target cognitive domains including attention, working memory, processing speed, and problem solving. Both groups completed the training program across eight weeks. Results indicated a significant gain in academic selfefficacy for the experimental group on the post-treatment measurement. These students reported greater competence in their abilities for reading, studying, test-preparation, and note taking compared to the control group.

More recently, Mawjee, Woltering, and Tannock (2015) conducted a study to determine whether a standard-length computerized training program enhanced working memory and if so, whether the effects transferred to other cognitive domains and were sustained over time. The research team controlled for motivation, engagement, and expectancy. A sample of 97 postsecondary students with ADHD were randomly assigned to three treatment groups: a standardlength (45-minute session) adaptive Cogmed WM training (CWMT); a shortened (15-minute session) adaptive version of the CWMT that controlled for motivation, engagement and expectancy of change; and a control group that did not receive training. The three groups received phone calls weekly from trained coaches who supervised the training and were not part 
of the research team. All participants were evaluated before training and three weeks after training. Those participants in the two experimental groups were also assessed three months post-training. Untrained outcome measures of WM included the WAIS-IV Digit Span (auditoryverbal WM), WRAML Finger Windows (visual-spatial WM), and the CANTAB Spatial Span (visual-spatial WM). Transfer effects were based on the following trained processes: cognitive speed, complex reasoning, short-term memory, reading and math fluency, and ADHD symptoms. Results from Mawjee et al. (2015) revealed that the shortened CWMT treatment conferred as much benefit on WM performance as the standard-length training on five of the seven criterion measures, with both groups improving more than the control group. However, only two of these findings remained robust after correcting for multiple comparisons. Additional analyses indicated improvements on WM performance after training were maintained for a minimum of three months. There was insufficient evidence to suggest any transfer effects. However, the standard-length group displayed improvement in task-specific strategy which was a key finding in the study.

Finally, Gropper, Gotlieb, Kronitz, and Tannock (2014) conducted a study to determine the feasibility and effectiveness of WM training in college students with ADHD or a learning disability (LD). The sample included 62 students who were randomly assigned to a five-week intensive WM training program or a wait-list control group. Participants were evaluated three times during the study including before treatment, during a three-week follow-up, and at a twomonth follow-up. Gropper et al. (2014) used standardized tests of auditory-verbal and visualspatial WM as criterion measures. Additionally, the outcome measures included near transfer measures like cognitive tasks and far transfer measures such as academic tasks and behavioral rating scales. Findings from the study indicated that participants receiving WM training showed 
significantly greater improvements on the criterion WM measures and reported fewer ADHD symptoms and cognitive failures at the three-week follow-up than those participants in the control group. At the two-week follow-up, it was revealed that gains in WM and decreased cognitive failures were maintained for the experimental group.

Attention issues. Emerging adulthood is a distinct developmental stage. During this stage, the prefrontal cortex, responsible for executive function and attention, continues to form and neural pathways are both pruned and strengthened (Johnson et al., 2009). Arnett (2000) defined emerging adults as individuals who are between 18 and 25 years old who face the developmental task of becoming increasingly independent and autonomous. Approximately $60 \%$ of emerging adults go on to pursue higher education (Brock, 2010). Thus, research on this population is highly relevant to university administrators and practitioners because many college students are also emerging adults.

Studies have shown that students with disabilities, including those individuals with clinically significant attention issues, struggle to adjust to the demands of college life (DaDeppo, 2009). Approximately $2-8 \%$ of college students and over $25 \%$ of college students with a diagnosed disability report clinically significant levels of ADHD (DuPaul et al., 2009). While many students are diagnosed prior to or during college, research has indicated that many students are not diagnosed due to subclinical symptoms of ADHD (Bussing, Mason, Bell, Porter \& Garvan, 2010). Prevalence rates of subclinical ADHD range from 5-10\% among the limited number of studies that have examined subclinical symptoms in young adults (Bussing et al., 2010; Gudjonsson, Sigurdsson, Smari \& Young, 2009). As a result, the number of college students with attention concerns may be underrepresented in the literature. 
Academic performance. The rigorous cognitive demands placed on students at the postsecondary level can be challenging for any student, but particularly for those individuals with ADHD and other learning-related concerns. College students with ADHD, for example, demonstrate significantly lower academic performance than their peers (Culpepper, 2011). Postsecondary coursework requires cognitive and non-cognitive skills such as attention, reasoning, self-control, motivation, and self-efficacy to modulate performance and foster academic success (Nagaoka et al., 2013). Motivation and self-control tend to be problematic for those with ADHD. Using positron emission tomography (PET), Volkow et al. (2011) identified decreased function in the dopamine pathway, which provides support for deficits in motivation, in adults with ADHD compared to adults without ADHD. Deficits in motivation could lead to low academic achievement for students with ADHD.

Response control is the ability to restrain one's impulses and is a function that is often lacking in individuals with ADHD. The ability to inhibit one's impulses is necessary for academic success, as Gutman and Schoon (2013) found a positive relationship between response control and academic achievement. Unfortunately, these factors are also concerning for individuals diagnosed with ADHD because the deficits in impulse control common in this disorder negatively correspond with academic achievement (Barkley, 1997; Green \& Rabiner, 2012; Gutman \& Schoon, 2013; Volkow et al., 2011).

Colleges and universities have sought to provide specialized services for students with ADHD by offering access to pharmacological and nonpharmacological resources. However, institutions have placed greater emphasis on nonpharmacological treatment modalities like cognitive training, given long-standing concerns about stimulant abuse in emerging adult populations (e.g., Flory, Payne, \& Benson, 2014; Liakoni, Schaub, Maier, Glauser, \& Liechti, 
2015). While cognitive training can be administered to any person, its use in college settings could be especially impactful for those students with clinically significant attention concerns. Culpepper (2011) indicated that students with attention deficits who receive proper treatment and resources can perform at the same academic level as their peers. Students with ADHD who are more advanced in college (e.g., seniors) may have greater internal and external resources for managing their ADHD symptoms than those who are earlier in their college tenure (e.g., freshmen). Therefore, I included school classification (e.g., freshman and sophomore) as a variable of interest in the current study.

\section{Summary}

It is evident from previous literature that college students, particularly those who report significant attention concerns, could benefit from cognitive training programs (Gropper et al., 2014; Mawjee et al., 2015). The relational component of the cognitive training program utilized in this study could offer academic, cognitive, and developmental benefits for clients. Further, the focus on fostering a growth mindset, metacognition, and scaffolding techniques in cognitive training programs that have a coaching component could help clients improve their cognitive abilities in ways that surpass traditional cognitive training programs. Finally, cognitive training programs can offer a substance-free intervention to mitigate the negative consequences of stimulant abuse on college campuses.

The psychology field is just beginning to understand the key active ingredients for the development of cognitive training methods that maximize cognitive and functional gains in individuals. Given the inconsistent results in the outcome literature and ongoing criticism relative to the commercial distribution of brain training programs, more research is needed to determine whether these benefits can be applied to a cognitive training program that incorporates 
a coaching element. Most traditional cognitive training interventions found in the literature report that progress monitoring occurs remotely with the clinician calling the client once a week for a phone-based consultation. In contrast, this study examined the efficacy of a cognitive training intervention in which direct and tailored feedback were foundational aspects of the program. Additional research is needed on the efficacy of cognitive training among emerging adult populations. As discussed, the cognitive training literature has mainly focused on populations such as children and elderly individuals (Melby- Lervåg \& Hulme, 2013). Thus, this study sought to examine whether similar results could be found for a sample of college students. Considering the dearth of cognitive training research among emerging adults, I initiated this study with the hope of informing future research concerning best practices for this unique population.

\section{Research Questions and Hypotheses}

The aim of this dissertation was to examine the effects of a cognitive training program with a coaching element on attention and response control in a sample of college students. This study also explored the potential effect of demographic variables, including the experience of the clinician and academic classification of the participant (e.g., underclassmen, upperclassmen, and graduate students) on treatment outcome as measured by attention and response control. This study serves as an initial exploration of a new cognitive training model (Long, 2017) that has the potential to be highly utilized in college counseling centers. The current study attempted to answer the following research questions:

1. Will there be a significant difference in score as measured by the average score on the global scales on the IVA-2 (Full Scale Attention Quotient and Full Scale Response 
Control Quotient) for participants when comparing performance before treatment to after treatment?

2. Is there a significant difference in attention as measured by the Full Scale Attention Quotient (FSAQ) before and after the cognitive training intervention as measured by the Integrated Visual and Auditory (IVA-2) and Continuous Performance Test (CPT)?

3. Is there a significant difference in the total averaged score of the Full Scale Attention Quotient (FSAQ) and Full Scale Response Control Quotient (FSRCQ) before and after the cognitive training intervention as measured by the Integrated Visual and Auditory (IVA-2) and Continuous Performance Test (CPT)?

4. Does the combination of predictor variables (school classification and clinician experience) significantly predict the total averaged score of attention as measured by the Full Scale Attention Quotient (FSAQ) and response control as measured by the Full Scale Response Control Quotient (FSRCQ)?

Based on a review of the relevant literature and research questions, the following hypotheses were proposed for the current study:

H1: There will be a significant increase in the average of the global scales on the IVA-2 (Full Scale Attention Quotient and Full Scale Response Control Quotient) for participants when comparing performance before treatment to after treatment.

H2: There will be a significant increase in the global score for response control on the IVA-2 (Full Scale Response Control Quotient) for participants when comparing performance before treatment to after treatment. 
H3: There will be a significant increase in the global score for attention on the IVA-2 (Full Scale Attention Quotient) for participants when comparing performance before treatment to after treatment.

H4: The combination of predictor variables (school classification and clinician experience) will significantly predict the composite score of attention as measured by an average of the Full Scale Attention Quotient and Full Scale Response Control Quotient. The remaining chapters of this dissertation will detail the methodology, results, and implications of this study. 


\section{CHAPTER 2: RESEARCH DESIGN AND METHODOLOGY}

\section{Research Design}

A within-subjects design was administered in this study using archival data. The data were collected at a large, public university and scores were compared before and after a cognitive training intervention. The archived participant data was gathered from students who sought cognitive training over two to fourth months at the university's counseling center between 2014 and 2017. All of the participants engaged in an initial diagnostic screening lasting one hour and were offered a range of treatment options, including psychotherapy, tutoring, medication, or cognitive training. Clients who opted for the cognitive training intervention were further screened by the testing director to determine whether this program was clinically indicated.

Demographic data for this study was collected via an intake process at the college counseling center and the outcome data was obtained through the Continuous Performance Test (CPT) database. This secondary research design was selected in order to determine the relationships among certain demographic variables (class standing and experience level of clinician) and outcome measures like global quotients of attention and response control. The archival design allowed the researcher to study previously gathered data. Data such as intake records and performance tests were also examined to gather information about the presenting symptoms of the sample. All of the data was gathered at a college counseling center and is thus, classified as field information.

\section{Participants}

The researcher analyzed data that was collected from clinical records of enrolled college students at a large, public university who sought services through the university's counseling center. This study's target population included students who reported difficulties with paying 
attention, including issues with sustaining attention in class, reading assigned texts, and completing assignments in a timely manner. In sum, the participants came from a deficit pool.

Inclusion criteria. Participants were required to meet specific, pre-identified criteria in order to be included in this study. All participants were 18 years or older and, at the time of the intervention, were enrolled in a degree-seeking program at the university. Additionally, participants must have been identified as impaired by the CPT measure $(<80)$ on either the Full Scale Attention Quotient (FSAQ) or Full Scale Response Control Quotient (FRCQ) prior to training. Finally, all participants had to commit to the 10 -week training regimen recommended by the counseling center, completing two sessions per week for a total of 20 sessions. To be included in the study, participants had to consent to using their data for research purposes on the intake paperwork.

The G*Power 3 program (Faul, Erdfelder, Lang, \& Buchner, 2009) was used to conduct an a priori power analysis prior to the data analysis to establish an appropriate sample size for the study. I computed the analysis using a large effect size of 0.35 , two predictor variables (school classification and clinician experience), and a statistical power of 0.95 , which indicated the need for at least 35 participants to achieve the necessary power. Both the effect size and power for this study are consistent with previous literature on cognitive training (Jaeggi et al., 2010).

\section{School Classification and Clinician Experience}

Table 1 shows the descriptive statistics of the participant sample in terms of school classification (underclassmen, upperclassmen, and graduate/professional students), one of the independent variables of interest. Underclassmen were defined as freshmen and sophomore students and upperclassmen were defined as junior and senior students. Table 2 shows the clinicians' experience with the cognitive training intervention, based on whether the clinician 
was a professional staff member or an unlicensed trainee. The coaches' experience with the cognitive training program ranged from four months to eight years. The professional staff member group was defined as those individuals who were licensed clinical psychologists during the cognitive training intervention. The unlicensed trainees group included those clinicians who were seeking supervision from a licensed psychologist at the time of the intervention.

Table 1

School Classification of the Participant Sample

\begin{tabular}{llc}
\hline Year in School & $N$ & $\%$ \\
\hline Underclassmen & 12 & 30.8 \\
Upperclassmen & 16 & 41.0 \\
Graduate/Professional Students & 11 & 28.2 \\
\hline
\end{tabular}

Table 2

Descriptive Statistics of Clinician Facilitators

\begin{tabular}{llc}
\hline Experience of the Clinician & $N$ & $\%$ \\
\hline Professional Staff Member & 23 & 60.0 \\
Unlicensed Trainee & 16 & 40.0 \\
\hline
\end{tabular}

\section{Measures}

Standardized data set. Demographic data was collected using the Standardized Data Set (SDS; Center for Collegiate Mental Health, 2017). This questionnaire is a set of standardized questions used in college counseling centers to collect demographic information during the intake process (APPENDIX B). In the current study, participants provided demographic information such as their academic level. The researcher used this data to assess how this variable may contribute to variances in performance of participants on the Continuous Performance Test (CPT). 
Integrated visual and auditory continuous performance test. The Integrated Visual and Auditory Continuous Performance Test (IVA-2 CPT; Sanford \& Turner, 1995) is a visual and auditory attention and response control that aids in the screening and diagnosis of attention deficit hyperactivity disorder (ADHD) symptomatology in individuals ages six and older. During the screening, the test-taker is tasked with monitoring the presence of both auditory and visual targets, presented as the numbers "1" and "2" (Quinn, 2003). The test lasts approximately 15 minutes including 12 minutes of active test taking and the results can evaluate treatment changes in participants. Given that the CPT has been shown to render only small practice effects in normal adults, it was well suited for this study (Stanford \& Turner, 1995).

The IVA has two global scales: the Full Scale Response Control and the Full Scale Attention Quotient. The Full Scale Response Control Quotient measures errors of impulsivity and commission errors and is composed of three subscales: Prudence, Consistency, and Stamina (Stanford \& Turner, 1995). The Full Scale Response Control Quotient is a global measure of the overall ability for this individual to regulate his or her responses and respond appropriately (response control). Factors that load on this scale include the ability to inhibit responses to nontargets, the consistency of recognition reaction times and the person's ability to maintain his or her mental processing speed during the IVA-2 test. Likewise, the Full Scale Attention Quotient measures attending and omission errors, and it compiles scores from the Vigilance, Focus, and Speed subscales. The Full Scale Attention Quotient provides a measure of an individual's overall ability to accurately and quickly respond while maintaining focus (attention). This global scale primarily measures performance under low demand conditions. Scores that are 80 or below are reported as statistically significant, which is 1.5 standard deviations from the mean. Quotient scores for all IVA-2 scales are reported as standard scores $(M=100, \mathrm{SD}=15)$. 
Quinn (2003) found that in assessing the IVA's validity, the test yielded a 92\% sensitivity and $90 \%$ specificity, and concurrent validity with other similar instruments. Additionally, the IVA yielded concurrent validity of $90 \%$ when compared to other Continuous Performance Tests such as the TOVA CPT, the Gordon CPT, and the Conners Abbreviated Symptom Questionnaire (Quinn, 2003). A study examining the test-retest reliability of the IVA over a four-week period revealed correlations ranging from .37 to .41 for the Auditory Response, Visual Response, and Full Scale Response Controls. One possible reason for the low test-retest reliability scores on the Response Control scales could be due to an increased vigilance by participants of target patterns. A change in errors of commission may be in response to the expectation of upcoming targets due to familiarity with the measure. In the same study, correlations for the Full Scale Attention Quotient, Auditory, and Visual Attention Quotient ranged from .66 to .75 (Seckler, Burns, Montgomery, \& Sandford, 1995). The normative database contains data from 781 voluntary participants without impairments, ranging from 5 to 90 years old (Sandford \& Turner, 1995).

Training for coaches. The trainee coaches for this study consisted of doctoral level graduate students and predoctoral interns completing their American Psychological Association (APA) approved internship, in addition to the Coordinator of Testing at the counseling center. The expertise level for the coaches ranged from one semester of coaching to several semesters, and in a few instances, years. Coaches would volunteer services for the cognitive training clinic at the beginning of each fall and typically serve for a year.

During individual and group supervision, coaches received guidance from a licensed clinician about cognitive training techniques and treatment plans. Training emphasized a standardized protocol of selected games for all participants. Afterwards, coaches discussed with the licensed clinician the strengths and weaknesses of the individual client. Beyond the 
individual treatment plans, training for coaches focused on the alliance created between the coach and participant. The cognitive training program studied in this dissertation was cliniciandriven. As instructed in the training, coaches might have observed behavioral changes in the participant that were considered in conjunction with information gleaned from the game results. Coaches would use their observations and the objective data from the game to scaffold the task or try a new approach.

In session, coaches were encouraged to challenge and support clients through techniques such as scaffolding and metacognition. For the purposes of tailoring the training program to the individual participant, no specific theoretical orientation was used to foster growth in the client. Instead, clinicians focused on the common factors proposed by Wampold (2015), such as the therapeutic alliance, empathy, client's expectations, cultural adaptation, and therapist differences. Person-centered and motivational interviewing (Miller \& Rollnick, 2013) techniques were demonstrated as a part of the coaching component, including partnering with the client, creating a space of acceptance and affirmation, summarization, and affirmations (Mason, 2009). Coaches would process the participant's feelings about a task or session to gauge the participant's selfassessment of their performance. While the cognitive training program had a standardized protocol in many ways, the coaching element was variable for each client depending on their specific needs and functioning, in addition to the style of the coach.

\section{Procedures}

Participants in this study presented to the university counseling center with attention concerns. Either by phone or in person, the participant scheduled for a 90-minute diagnostic screening. Upon arriving for their screening appointment, the participant competed paperwork 
including the Standardized Data Set (SDS; APPENDIX B) and informed consent and privacy practices. The privacy statement, as relevant to the current study, read:

We may disclose health information to researchers when the university's institutional review board has reviewed and approved the research proposal and established protocols to ensure the privacy of your health information. This information is generally deidentified. (Gold, 2015 p. 51)

This statement and the student's signature ensured that all participants were adequately informed of the university's policies on sharing information and consent, and that they agreed to the inclusion of their de-identified information in subsequent studies.

Upon completion of these documents, each student then completed an electronic intake assessment, conducted on a secure computer in the counseling center. First, the SDS (APPENDIX B) was presented, which assessed demographic and background information. Each question is presented sequentially and varies in potential answers from forced choice to free response. Upon completing this assessment, the student returned to person at the front desk who then informed the attending provider that the initial intake was completed.

The clinician reviewed the paperwork and then conducted a brief conversation with the client about their motivation for seeking services, as well as discussing goals and current coping techniques. This conversation provided the clinician a medium for assessing the student's readiness for change as well as fit within the growth mindset framework (Norcross, Krebs, \& Prochaska, 2011). The clinician then conducted an interview about various factors that affect cognitive function, such as sleep, eating, substance use, and academic history. This information provided the clinician with a more holistic conceptualization of the student and his/her needs. After completing the clinical interview, the student was then asked to complete the IVA-2 CPT 
on a computer. The student was seated at a computer, given headphones and a mouse, and was instructed by the clinician to follow the directions on the computer screen. Upon completion of the test, the clinician explained the results (i.e., FSAQ and FSRCQ scores) to the student and proposed a treatment plan. If clinically appropriate, participants were referred for cognitive training.

Cognitive training intervention with coaching. Clients who met criteria and agreed to cognitive training completed the intervention in 20 sessions over two to four months. The IVA-2 CPT was re-administered on the last session. Captain's Log MindPower Builder was the software used to administer the working memory and attentional tasks. In each session, the participant received coaching from the clinician, as well as feedback from the Captain's Log computer software program which consists of over 2000 exercises targeting various cognitive skills. Through the program, participants were presented with visuospatial, verbal, and auditory working memory (WM) tasks. These tasks required the manipulation and storage of either visuospatial information or auditory information. After each session, the participant received feedback in the form of a completion percentage, as well as advancement to more difficult levels. While Captain's Log was the medium through which the program was delivered in this study, the intervention was largely clinician-based. This intervention relied on creativity and adaptability by the clinician to assess, identify, and match the appropriate task with the deficit observed. For instance, auditory working memory is an area commonly addressed in cognitive training using reverse recall. One strategy used by clinicians to address this area of working memory is a recoding task. The goal of this task is to recall a series of words in reverse order. For example, the participant might be asked to reverse recall colors such as red, orange, green, blue, yellow, black, and purple. Several strategies can help the client achieve this task including 
chunking, which involves grouping information into smaller portions, or stringing the first letter of each word together to form a nonsense word (i.e. ROGYBYBP) which locks in the order of the colors. This exercise requires the brain to complete several tasks at once including listening, separating the letters, holding information previously heard and listening for new letters, recycling processes $1-3$, blending individual letters separated from the words into a singular nonsense word, and reversing recall all colors. Each of the six tasks for this recoding strategy require the individual to use an area of working memory or attention: listening requires auditory attention; separating the letters requires selective attention; holding information and listening for new words requires retaining information in the phonological loop and resisting; recycling steps 1-3 depends on alternating attention; making a sound uses phonological blending; and reverse recall elicits recall from the phonological loop and selection by the central executive.

Throughout the program, the clinician would engage in a cyclical process of testing, assessing, and reassessing the participant's cognitive skills. Scaffolding, a process of helping the client attain the next level of achievement, is an important aspect of the program. If, for example, the clinician determined that the participant struggled with selective attention, they may have incorporated selective attention tasks over the course of several appointments to help the client "level up." The clinician was responsible for determining the appropriate challenge level, and thus adjusted and customized the treatment plan based on the participant's individual performance. This was the coaching element of the training and its importance as a core aspect of the training cannot be overstated (Long, 2017).

Sampling. Ideally, this study would have utilized random sampling. However, the archival nature of the data rendered this sampling method impossible. Archival data has both advantages and disadvantages. An advantage of this type of research is that the researcher does 
not have to be concerned about mistakenly introducing changes in participant behavior that might affect the results of the study (Heppner, Kivlighan, \& Wampold, 1999). Archival data is cost effective and has the advantage of spanning long periods of time. Thus, the use of this type of data offers the possibility of a wider perspective of trends and outcomes (Heppner et al., 1999). One of the disadvantages of archival research is that the data may be unreliable or not collected to the present researcher's standard as the researcher does not have control over how the data was collected (Heppner et al., 1999). As a result, the data may be incomplete or may not address key issues of the present study. Despite some disadvantages, the researcher believed that this methodology was fitting for the purposes of the current study.

\section{Data Collection}

After receiving approval from the Institutional Review Board (IRB; APPENDIX A), the archival data from 2014 to 2017 was obtained from electronic reports from the college counseling center. After all of the data was gathered, software was used to generate reports with requested queries and de-identified student data. The reports included self-reported responses on the SDS (APPENDIX A), which allowed for the collection of information related to the independent variable of school classification. The report eliminated students who failed to respond to the requisite information fields. Boswell et al. (2012) utilized this same methodology to examine the relationship between the Counseling Center Assessment for Psychological Symptoms (CCAPS), SDS, and depressive symptomatology in college students. Following deidentification, the data was compiled in an encrypted spreadsheet in preparation for the multiple regression analysis. Likewise, FSAQ and FSRCQ scores for each participant were collected from the IVA-2 CPT computer program and entered into an excel spreadsheet in preparation for t-test and regression analysis. All of the data was gathered under the supervision of the 
counseling center's director to ensure the proper handling of sensitive student data. The researcher conducted the analysis on a secure, university-owned computer located at the university. The information was stored on an encrypted flash drive and the information will be maintained for future research. After seven years, the data for this study will be permanently deleted.

\section{Data Analysis}

After the data was gathered and coded, it was entered into the Statistical Package for Social Sciences, SPSS (IBM Corp, 2017). In addition to a variety of summary statistics, this study used bivariate correlations, $t$-tests, and multiple regression to explore relationships within the data. Prior to testing each hypothesis, Pearson product-moment correlation coefficients were conducted to assess the relationship between each of the predictors independently (school classification and clinician experience) and the dependent measures IVA-2 CPT, which included outcomes such as global attention and response control quotients (Full Scale Attention Quotient and Full Scale Response Control Quotient) and an average score of the two quotients. A correlation matrix was developed as a result.

Hypothesis 1. First, it was hypothesized that there would be a significant increase in the average of the global scales on the IVA-2 (Full Scale Attention Quotient and Full Scale Response Control Quotient) for participants when comparing performance before and after treatment. The researcher conducted a paired samples $t$-test comparing the average of the global scales on the IVA-2 CPT to test this hypothesis.

Hypothesis 2. In the second hypothesis, the researcher anticipated that there would be a significant increase in the global score for response control on the IVA-2 (Full Scale Response Control Quotient) for participants when comparing performance before treatment to after 
treatment. The researcher conducted a paired samples $t$-test comparing global score for response control on the IVA-2 CPT to test this hypothesis.

Hypothesis 3. The third hypothesis stated that there would be a significant increase in the global score for attention on the IVA-2 (Full Scale Attention Quotient) for participants when comparing performance before treatment to after treatment. The researcher conducted a paired samples $t$-test comparing global score for attention IVA-2 CPT to test this hypothesis.

Hypothesis 4. The fourth hypothesis stated that the combination of predictor variables (school classification and clinician experience) will significantly predict the composite score of attention as measured by an average of the Full Scale Attention Quotient and Full Scale Response Control Quotient. This was addressed using a multiple linear regression analysis. This statistical method helped the researcher to identify the contributions of the predictor variables respective to variability in the criterion variable (Heppner et al., 1999). Prior to the multiple regression analysis, a Pearson product-moment correlation was conducted to assess the relationship between school classification and an average of the Full Scale Attention Quotient and Full Scale Response Control Quotient. A second Pearson product-moment correlation was conducted to assess relationship between clinician experience and an average of the Full Scale Attention Quotient and Full Scale Response Control Quotient. A stepwise regression method was implemented to enter the predictor variables in the regression model accordingly.

Predictor variables. This study assessed whether clinician level and school classification served as mediators or moderators in the regression model. The exploration of these variables was due to an acknowledgement that behavior is complex and that experiences vary across individuals. To assess if the predictor variables (school classification and clinician experience) explained a statistically significant amount of variance in the dependent variable 
after accounting for all other variables, a regression was used. In this framework, several regression models were constructed utilizing a forced entry approach, given that the research on cognitive training theory is limited. In sum, this analysis allowed the researcher to determine which combination of predictor variables, if any, significantly predicted the criterion variable. 


\section{CHAPTER 3: RESULTS}

Data was collected from a total sample of 55 participants from 2014 through 2017 . Of the initial 55 participants, $39(70.9 \%)$ provided complete and valid response sets on both measures of the continuous performance test of attention (IVA-2 CPT) and therefore, were included in the final analyses. In the sample of 39 participants, 33 were male $(84.6 \%)$ and 6 were female $(15.4 \%)$.

\section{Coding and Scoring}

The categorical variables of school classification and clinician experience were dummy coded before the data were analyzed. Regarding school classification, upperclassmen served as the reference group due to it being the largest subgroup. Additionally, the professional staff member group served as the reference group for clinician experience because it was the larger demographic of the two groups. Total pre-intervention and post-intervention IVA-2 global scores were calculated by averaging the two IVA-2 global scales (Full Scale Attention Quotient and Full Scale Response Control Quotient) for both the pre-intervention and post-intervention, then creating a new singular unit of measure for pre-intervention and post-intervention which is referred to as the composite score. The mean pre-intervention IVA-2 score was $63.63(S D=$ 18.68) and the mean post-intervention IVA-2 score was $95.59(S D=17.06)$.

\section{Paired Samples $t$-Tests}

A total of three paired samples $t$-tests were conducted to test $\mathrm{H} 1, \mathrm{H} 2$, and $\mathrm{H} 3$ to determine if there were significant differences between pre-intervention and post-intervention IVA-2 CPT scores. To reduce the risk of Type I error for the multiple analyses of a single data set used in this study, a Bonferroni correction was used. Therefore, the four a priori hypotheses were conducted using adjusted alpha levels of .0125 per test (.05/4). The first hypothesis 
predicted that there would be a significant increase in scores as measured by the average score on the global scales on the IVA-2 (Full Scale Attention Quotient and Full Scale Response Control Quotient) for participants when comparing performance before treatment to after treatment. In support of H1, there was a statistically significant difference between IVA-2 global scores $(M=$ 31.96, $S D=20.10.), t(38)=9.929, p<.001$ (See Table 3). Cohen's $d$ was estimated at 1.76, which is a large effect based on Cohen's (1992) guidelines. Therefore, the results indicate the null hypothesis of equal scores was rejected and the post-training mean was significantly higher than the pre-training mean. It should also be noted that the correlation between the two conditions was estimated at $r=.370, p=.020$, suggesting that the paired samples $t$-test was appropriate in this case.

The second hypothesis predicted that there would be a significant increase in the global score for response control on the IVA-2 (i.e., Full Scale Response Control Quotient) for participants when comparing performance before treatment to after treatment. H2 was supported, as there was a statistically significant difference in the global score for response control on the IVA-2 (Full Scale Response Control Quotient) for participants when comparing performance before treatment to after treatment $(M=28.64, S D=28.61), t(38)=$ $6.25, p<.001$ (See Table 3). Cohen's $d$ was estimated at 1.28 which is a large effect based on Cohen's (1992) guidelines. Therefore, the results indicated that the null hypothesis of equal scores was rejected and the post-training mean was significantly higher than the pre-training mean. It should also be noted that the correlation between the two conditions was estimated at $r$ $=.21, p=.19$, which is lower than what is expected with the use of a paired-samples $t$-test; however, the use of a paired $t$-test is justified as the reason for the low correlation is due to the dramatic increase in the subjects' ability to control their responses after the intervention. The 
large change in scores between pre-intervention and post-intervention was greater than the attention quotient, suggesting that it may be easier to train response control using this intervention with a coaching component than other aspects of attention. Furthermore, for this hypothesis a related measure of effect size Hedges $g$ may be more appropriate than Cohen's $d$ due to correlation concerns. Hedges $g$ for $\mathrm{H} 2$ is 0.712 .

Lastly, H3 was supported, suggesting a significantly significant difference in scores on the Full Scale Attention Quotient, a global measure for attention on the IVA-2 $(M=35.28, S D=$ 28.67), $t(38)=7.69, p<.001$ (See Table 3$)$. Cohen's $d$ was estimated at 1.45 , which is a large effect size based on Cohen's (1992) guidelines. Therefore, the results indicated the null hypothesis of equal scores was rejected and the post-training mean was statistically significantly higher than the pre-training mean. It should be noted that the correlation between the two conditions was estimated at $r=.31, p=.053$, suggesting that the paired samples $t$-test was not appropriate in this case. A related measure of effect size Hedges $g$ may be more appropriate than Cohen's d due to correlation concerns. Hedges $g$ for $\mathrm{H} 3$ is 1.43 .

Table 3

Descriptive Statistics and t-test Results for Composite, Response Control, and Attention

\begin{tabular}{|c|c|c|c|c|c|c|c|c|c|}
\hline \multirow[b]{2}{*}{ Outcome } & \multicolumn{2}{|c|}{ Pretest } & \multicolumn{2}{|c|}{ Posttest } & \multirow[b]{2}{*}{$\mathrm{n}$} & \multirow{2}{*}{$\begin{array}{c}95 \% \text { CI for } \\
\text { Mean Difference }\end{array}$} & \multirow[b]{2}{*}{$\mathrm{r}$} & \multirow[b]{2}{*}{$\mathrm{t}$} & \multirow[b]{2}{*}{$\mathrm{df}$} \\
\hline & $\mathrm{M}$ & SD & $\mathrm{M}$ & SD & & & & & \\
\hline $\begin{array}{l}\text { Composite } \\
\text { (H1) }\end{array}$ & 63.63 & 18.89 & 95.59 & 17.06 & 39 & $25.45,38.48$ & .37 & $9.93 * *$ & 38 \\
\hline $\begin{array}{l}\text { Response } \\
\text { Control (H2) }\end{array}$ & 66.80 & 27.30 & 95.43 & 16.19 & 39 & $19.37,37.91$ & .21 & $6.25^{* *}$ & 38 \\
\hline $\begin{array}{l}\text { Attention } \\
(\mathrm{H} 3)\end{array}$ & 60.46 & 26.88 & 95.74 & 21.41 & 39 & $25.99,44.57$ & $.31 *$ & $7.69 * *$ & 38 \\
\hline
\end{tabular}

Note. $* \mathrm{p}<.05 ; * * \mathrm{p}<.0125$ 


\section{Multiple Regression Analyses}

Statistical assumptions. Multiple regression analyses were conducted to analyze the impact of the two predictor variables (classification in school and clinician experience) on several outcome measures of attention and response control as measured by the IVA-2 CPT (FSAQ, FSRCQ, and a combination of both the FSAQ and FSRCQ). For this study's results to be considered valid, several assumptions had to be met before the data were analyzed. The researcher tested six assumptions, including the independence of observations; linearity; homoscedasticity; multicollinearity; absence of significant outliers, influential points, or high leverage points; and normal distribution of residual errors. First, the Kolmogorov-Smirnov and Shapiro-Wilk tests were performed to assess for normality of distribution of the pre-test and post-test IVA-2 CPT scores. Specifically, this was assessed by examining a histogram of residual errors that compared the observed variance in IVA-2 scores with that of a normal distribution. Nonsignificant results for both tests suggested that the scores were normally distributed. The findings of the Kolmogorov-Smirnov test were not significant ( $p>.05$ ). The Shapiro-Wilk test was also not significant $(\mathrm{p}>.05)$. The non-significant result of the ShapiroWilk test suggested that we cannot reject the hypothesis that the sample comes from a population with a normal distribution. Likewise, the non-significant result of the Kolmogorov-Smirnov test suggested that the sample is unlikely to be skewed in either a positive or negative direction. The results of the histogram (Figure 1) support the findings of the Kolmogorov-Smirnov and Shapiro-Wilk tests. The histogram results showed an approximate normal distribution of scores. Additionally, the P-P Plot of standardized residual errors (Figure 2) also reflected that the scores are normally distributed. 


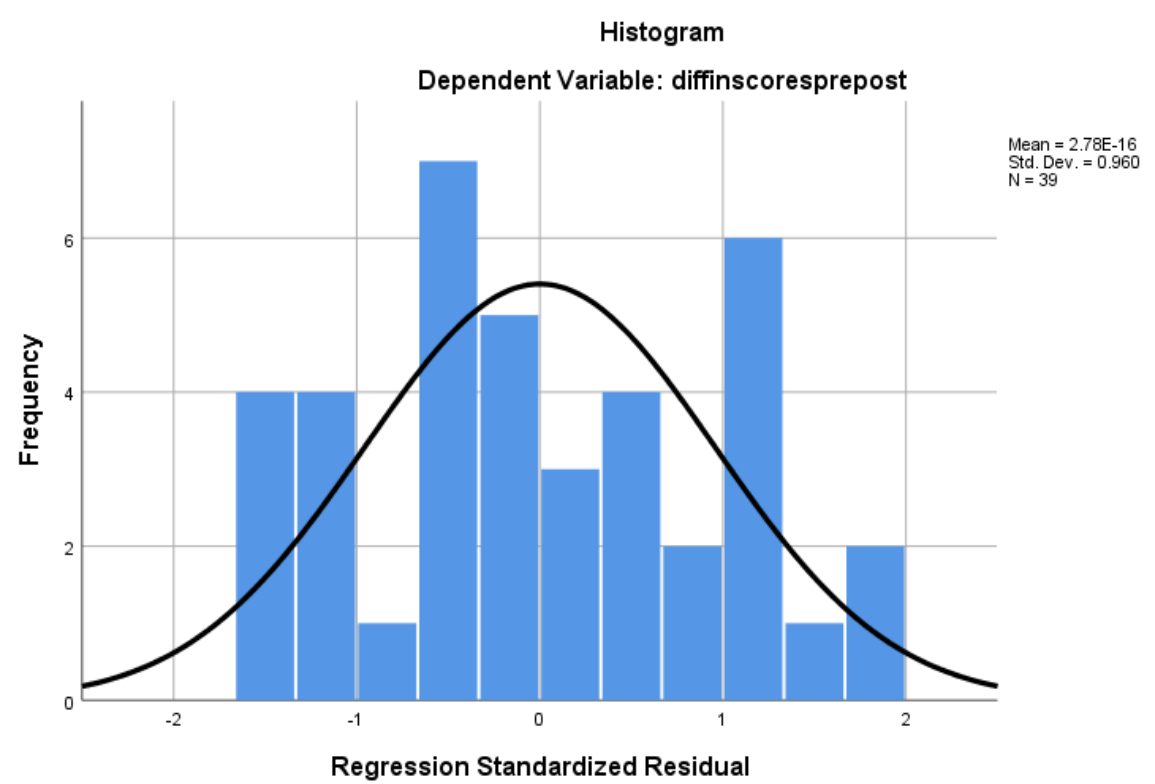

Figure 1. Standardized Residual Histogram.

Next, the Durbin-Watson test statistic assessed the assumption of independence of observations. According to the Durbin-Watson test, a statistic that falls within the cutoffs of dL $=1.187$ and $\mathrm{dU}=1.392$ for the sample size of $n=39$ is considered to have met this assumption (Savin \& White, 1977). The Durbin-Watson statistic $(d=1.37)$ fell between these cutoffs, indicating an inconclusive finding. In this context, the author chose to err on the side of conservatism and not reject the null hypothesis. A failure to reject the null hypothesis of the Durbin-Watson statistic suggests there was no correlation among the residuals, thus the assumption was met (Savin \& White, 1977).

Linearity was assessed by plotting the standardized residuals on a scatterplot (Figure 2). A review of the scatterplot suggests a linear relationship between predictor and dependent variables. Additionally, the residuals formed a band across the scatterplot and the residuals did not vary in range from the plotted line, suggesting that the assumption of homoscedasticity was also met. Furthermore, there were no outliers identified in the dataset following a review of the standardized residuals as all data points fell within three standard deviations of the mean. 
Moreover, values measured by Cook's distance were found to be less than 1.1, just slightly above the 1.0 recommendation for the statistic, and no leverage points were observed due to all leverage values being less than 0.2 (Cook, 1977). Lastly, the standardized residuals approximated a normal distribution (Figure 1). To further support these findings, results from a P-P plot (Figure 2) suggested that the assumption of normality was met as noted by the approximately normal distribution of scores along the diagonal line. The P-P plot revealed that the line of observed values followed the line that indicated a normal distribution. The data points represented scores on the IVA-2 CPT as calculated by the difference between pre-intervention scores and post-intervention scores.

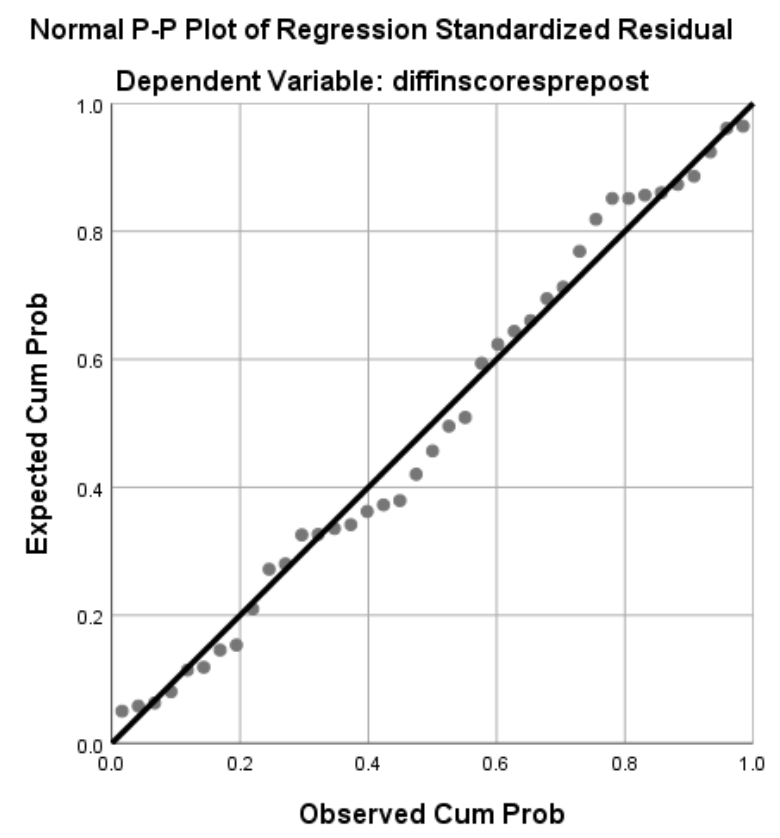

Figure 2. Normal P-P Plot of Standardized Residual.

\section{Results}

After meeting all of the required assumptions, a multiple regression analysis was conducted to assess the relationship between the two predictor variables (school classification 
and clinician experience) on the outcome variable from pre-intervention to post-intervention. The outcome variable for the multiple regression was the score of a singular unit of attention which was created by averaging the FSAQ and FSRCQ quotients. The scores were calculated by subtracting the difference in scores from post-intervention quotient from pre-intervention quotient for each of the participants.

The predictors in this study were not entered based on a core theory due to the heterogeneity of cognitive training studies. Rather, forced entry was utilized because the literature surrounding cognitive training predictors is limited. Results showed no statistically significant correlations among the predictors (Table 4), suggesting that multicollinearity among the predictor variables was unlikely.

Table 4

Correlations Between Predictors and Differences in Attention and Response Control

\begin{tabular}{llllll}
\hline \multicolumn{1}{c}{ Variable } & 1 & 2 & 3 & 4 & 5 \\
\hline 1. Difference in Scores & -- & & & & \\
2. Professional Staff & .09 & -- & & \\
3. Underclassman & -.27 & -.12 & -- & -- & \\
4. Upperclassman & .11 & .06 & -.56 & -.52 & -- \\
5. Graduate/Professional & .15 & .06 & -.42 &
\end{tabular}

Note. Correlations between variables were not statistically significant $(\mathrm{p}>.05)$

As seen in table 6 , there were no predictor variables found to be statistically significant. This likely contributed to the model being statistically nonsignificant. The amount of explained variance in the model was found to be extremely small and thus, not useful in generalizing the findings. The regression model in Table 6 revealed that $R^{2}$ accounted for roughly $8 \%$ of the variance' while adjusted $R^{2}$ accounted for $0.1 \%$ of the variance, $R^{2}=.0 .78\left(\Delta R^{2}=-.001\right), F(3$, 
$35)=0.99, p=.41$. Ultimately, the model was not statistically significant (see Table 6 and 7).

Despite not being able to determine which specific factors contributed to this improvement, the following chapter will offer potential explanations for these differences.

Table 5

Summary of Regression Analysis for Variables Predicting the Total Averaged Score of Attention $(n=39)$

\begin{tabular}{lccccc}
\hline Model & B & SE B & B & $t$ & Sig. \\
\hline (Constant) & 33.09 & 6.50 & & 5.09 & .000 \\
Staff & 2.45 & 6.60 & .061 & .371 & .713 \\
Underclassman & -10.36 & 7.73 & -.241 & -1.341 & .188 \\
Graduate/Professional & 2.17 & 7.88 & .049 & 2.75 & .785 \\
\hline
\end{tabular}

Note. Correlations between variables were not statistically significant $(\mathrm{p}>.05)$

Table 6

Model Summary of Multiple Regression Analysis for Variables Predicting the Total Averaged

Score of Attention

\begin{tabular}{cccccc}
\hline Model & $\mathrm{R}$ & $\mathrm{R}^{2}$ & $\Delta \mathrm{R}^{2}$ & $S E$ & Durbin-Watson \\
\hline 1 & .279 & 0.78 & -.001 & 20.11 & 1.37 \\
\hline
\end{tabular}


Table 7

Multiple Regression Analysis for Variables Predicting the Total Averaged Score of Attention ANOVA

\begin{tabular}{clccccc}
\hline Model & & $\begin{array}{c}\text { Sum of } \\
\text { Squares }\end{array}$ & $d f$ & $\begin{array}{c}\text { Mean } \\
\text { Square }\end{array}$ & $F$ & Sig. \\
\hline \multirow{2}{*}{1} & Regression & 1197.37 & 3 & 399.12 & 0.99 & 0.41 \\
& Residual & 12158.33 & 35 & 404.52 & & \\
& Total & 15355.69 & 38 & & & \\
\hline
\end{tabular}




\section{CHAPTER 4: DISCUSSION}

Previous literature has shown that academic performance is negatively impacted by clinically significant attention issues (Barkley, 1997; Green \& Rabiner, 2012; Gutman \& Schoon, 2013; Volkow et al., 2011). As increasing numbers of college students report such issues, postsecondary institutions have broadened available services to include academic accommodations and psychiatric medication (Culpepper, 2011). That said, some students with attention difficulties may not qualify for accommodations or may not use medication due to the potential for dependency or adverse side effects (Flory et al., 2014; Liakoni et al., 2015). To meet these demands, non-pharmacological interventions like cognitive training may be beneficial for students and university counseling centers. The aim of the present study was to explore the efficacy of a cognitive training program with a coaching element on the outcomes of attention and response control in a college student population. This study also sought to examine the predictive relationships between individual predictors (school classification and clinician experience) and the outcome variables (a summed average of attention and response control scores).

Given increasing empirical interest in cognitive performance, this study is timely. However, a review of the current literature revealed limited knowledge surrounding the efficacy of cognitive training programs with a coaching element. Further, individual factors of the participant and clinician have yet to be empirically explored. These deficits could be attributed to how past research studies have been designed. For instance, several studies were designed so that participants were not given direct feedback from a person but rather, from the computer software itself (Horowitz-Kraus \& Breznitz, 2009; Salminen, Strobach, \& Schubert, 2012). Other studies have examined the efficacy of cognitive training programs using non-clinicians, 
such as parents, to monitor performance, thus participants did not receive professional psychological feedback during the training (Borella et al., 2010; Holmes et al., 2010). Finally, some studies have examined programs in which clinicians call participants on a weekly or biweekly basis to assess their progress (Gropper et al., 2014; Mawjee et al., 2015).

In addition to variability in research design, there have been a wide range of outcomes reported by previous studies. For example, findings from Jaeggi, Buschkuehl, Joniedes and Shah (2011) support the notion that cognitive training positively affects an individual's cognitive performance. Additionally, some studies have demonstrated a moderate to large effect size of cognitive training on specific cognitive domains, known as near transfer effects (Knafo \& Venero, 2014). Near transfer occurs when the training situation is identical to the application of the learned skill or behavior. Considering the uncertainty regarding the far transfer effects of cognitive training, the current study sought to investigate whether a cognitive training intervention could improve near transfer effects, such as visual and auditory attention, in a sample of college students. There is strong evidence to support that scores on the Integrated Visual and Auditory Continuous Performance Test (IVA-2 CPT) would improve due to previous research on near transfer effects (Jaeggi, 2010). In contrast to Gropper et al. (2014), however, this study examined a program that included a clinician actively collaborating with the participant.

\section{Findings and Implications}

Findings from this study supported the first hypothesis; the differences in scores based on an average of the Full Scale Attention Quotient (FSAQ) and Full Scale Response Control Quotient (FSRCQ) were statistically significant. These findings, in addition to those for the second and third hypotheses, suggested that outcomes resulted from real change and not from 
practice effects. This is, perhaps, the most salient finding from this study. These findings are consistent with the literature, as Sandford and Sandford (2014) found that when retesting individuals using the IVA scores did not change beyond three to four points in either direction, suggesting that practice effects were unlikely. Because the IVA-2 CPT presents 500 trials of 1's and 2's lasting 13 minutes, it creates a pseudorandom condition and reduces the possibility of practice effects.

The rationale for averaging the two quotients in the current study was to prevent extreme scores on either of the quotients from artificially raising scores following training. For instance, a participant could have scored highly on the FSAQ by responding indiscriminately to the targets by clicking anytime a target appeared on the screen. The results would then suggest that the participant was highly attentive when in fact, they displayed limited response control during the task. It is difficult to significantly raise scores on both quotients simultaneously as it requires the participant to be both patient and engaged and thus, an averaged quotient score for the participants was warranted.

Findings from the first hypothesis were also consistent with results from similar studies in which the aim was to improve attention control (Peng \& Miller 2016). Peng and Miller (2016) discovered through a meta-analysis of working memory significant training effects of cognitive training on attention skills $(g=0.25)$. When converting the effect sizes to Hedges $g$, the effect sizes for this study dwarf that of the meta-analysis, with effect sizes ranging from $\mathrm{g}=0.712$ to $\mathrm{g}$ $=0.849$. These results support findings from Mawjee et al. (2015) in which cognitive working memory training improved working memory performance on tasks similar to the training tasks. In the present study, the outcome measure was a dual n-back test and training included a broad spectrum of tasks, such as storage and retrieval, attention control, interference management and 
maintenance of working memory. The tasks selected as part of the Captain's Log software used a variety of attention and response control components in addition to other working memory tasks. However, at the core of this training, the trained tasks emphasized attention and working memory, which is also assessed by the outcome measure.

Results from the current study also supported the second hypothesis as participants' scores significantly improved on the global measure of attention as measured by the FSAQ before and after the cognitive training program. This significant improvement revealed that the training program improved a combination of near transfer tasks captured by the FSAQ. Three components (vigilance, focus, speed) comprise the FSAQ and are measured by corresponding scales. The improved scores suggested that the participants were better at sustaining attention and responding consistently and more quickly to targets because of the cognitive training program.

Findings also supported the third hypothesis as participants' scores significantly improved on the global measure of response control as measured by the FSRCQ before and after the cognitive training program. Significant differences in scores on this quotient indicated that participants exhibited greater control of impulsivity as measured by errors of commission after the intervention. Participants were consistent in their reaction times to each target, which further suggested a heightened control of responses by the participant. Like the second hypothesis, results stemming from the third hypothesis are consistent with cognitive training studies that found transferability of working memory training on sustained attention and control (Mahncke et al., 2006, Richmond et al., 2011). That said, these studies focused on the transferability of working memory training on sustained attention and control in older adults. Results from the current study, however, extend these findings to emerging adults. 
Results from the current study yielded similar or greater effect sizes compared to similar studies without a coaching element. For example, Jaeggi (2010) reported observed effect sizes of 1.34 and 1.12 compared to the effect sizes of $1.76,1.28$, and 1.45 in this study. Findings from the current study as compared to Jaeggi (2010) suggested that the coaching element of the program may have significantly contributed to differences in participants' scores. This information is valuable as postsecondary institutions develop programs to address the growing need for mental health services for students with neurodevelopmental concerns.

Compared to the previous literature, the effect sizes for the present study were large. A meta-analysis conducted by Melby-Lervåg and Hulme (2013) found that most studies on cognitive training that utilized a working memory outcome variable reported an observed effect size less than 1.0. Melby-Lervåg and Hulme (2013) examined the effects of cognitive training and categorized the findings into two groups: near effects and far-transfer effects. Near effects, which are a more appropriate comparison for the current study, were further divided into three categories (i.e., verbal working memory, visuospatial working memory, and non-verbal working memory). The largest effect sizes for immediate effects were found in the visuospatial working memory. For instance, age was an important moderator, with young children having the largest effect size $(\mathrm{d}=1.41)$. Young adults, the most comparable group to this study, had an effect size of $d=0.74$ across the four studies. Likewise, there was a diverse set of intervention programs included in the meta-analysis with effect sizes ranging from 0.45 to 1.18 .

In this study, the observed effect sizes can be compared to the non-verbal working memory in the meta-analysis (Melby-Lervåg \& Hulme, 2013). Melby-Lervåg and Hulme (2013) defined measures of attention as tasks in which the participant must concentrate selectively on an aspect of the task while ignoring other aspects. This definition is comparable to what was asked 
of participants on some cognitive tasks in the present study. When compared to similar studies, the effect sizes in this study were larger than those found in the meta-analysis. In similar studies using training exercises with a computer program, the mean effect size was small to medium with a mean of $d=0.32$. This finding can be compared to the mean effect size in the present study $(\mathrm{d}=1.49)$. This difference is important, given that only two of the studies had a coaching component like the current study (Horowitz-Kraus \& Breznitz, 2009; Shiran \& Breznitz, 2011). For those studies, the effect sizes were $0.36 / 0.37$ and -0.16 respectively, which was substantially below what was observed for this study.

While it is difficult to compare cognitive training studies due to the numerous moderating variables (e.g., age, training dose, design, type of control, learner status, and intervention program), comparisons between similar moderators can be made. There were some moderators identified by Melby-Lervåg and Hulme (2013) that were similar to variables examined in the present study, including age, training dose, randomization, learner status, and intervention program. Interestingly, five of the six moderator categories identified by Melby-Lervåg and Hulme (2013) were also present in the current study. These moderators included adults $(\mathrm{d}=$ 0.33), a large training dose $(d=0.38)$, non-randomized $(d=0.48)$, unselected learner status $(d=$ $0.41)$, and other intervention program $(\mathrm{d}=0.31)$. While some of the moderators were shared, the effect sizes in the current study were considerably larger than in Melby-Lervåg and Hulme (2013). It is possible that this gap is explained by differences in variables, instruments, and/or the type of interventions administered.

In addition to analyzing training impact on near transfer effects (e.g., visual and auditory attention), the current study investigated two predictor variables (school classification and clinician experience level). Due to a lack of research on face-to-face cognitive training with a 
coaching component, the impact of these variables is largely unknown. Consequently, a strong theoretical foundation about this aspect of training has yet to be established. Regarding the variable of school classification, prior literature has indicated that students' ability to reason through intellectual problems and engage in critical thinking significantly improved due to college enrollment above and beyond chronological maturation (King \& Kitchener, 1994; Strange \& King, 1981). It was due to the explanation by King and Kitchener which led me to decide to use school classification and not age as a predictor variable. Futhermore, the researcher assumed that greater insight by the participant would allow them to better conceptualize their concerns and develop their own strategies during treatment. Considering this research on the development of critical thinking, it was hypothesized that students who have attended school for longer (such as graduate students) would perform better on the CPT following training than upperclassmen and lowerclassmen.

The second predictor variable, clinician experience, was selected because studies have shown that therapists do not become more effective with time and that experience has not been proven to be a significant predictor of effectiveness (Miller, Hubble, Chow \& Seidel, 2013). More recently, Goldberg et al., (2016) found that surprisingly, therapy outcomes worsened with clinician time and experience. While cognitive training and psychotherapy are not necessarily the same, there are several similarities between these interventions, including the importance of therapeutic rapport. Further, cognitive training often relies on motivational interviewing strategies to assist participants in reaching their goals. Hart, Blattner, and Leipsic (2001) specified differences between coaching and therapy. Coaching focuses on increasing a person's capacity to reach specified goals, while therapy is more focused on symptom reduction and making interpretations (Hart, Blattner, \& Leipsic, 2001). This difference is critical to 
understanding that cognitive training in this instance is more associated with coaching than with therapy, and thus the study by Goldberg et al. (2016) was not used as a foundation for the predictor variable clinician experience, although like the findings in the Goldberg et al. study, the participants did not perform worse with clinician experience. Ultimately, the researcher believed that experience with coaching would be beneficial and thus it was hypothesized that the attention of participants working with clinicians with the most experience (staff clinicians) would improve to a greater degree than those working with less experienced clinicians (i.e., interns and practicum students).

In contrast to the findings of the paired samples $t$-tests, the findings of this study did not support the fourth hypothesis, which stated that the combination of predictor variables (e.g., school classification and clinician experience) would significantly predict the total averaged score of attention as measured by the FSAQ and the FSRCQ. Although the results from the multiple regression analysis were not significant, this study still demonstrates relevant and important implications for cognitive training. For instance, the paired sample $t$-tests demonstrated significant differences in visual and auditory attention scores as measured by the FSAQ and FSRCQ from pre-intervention to post-intervention suggesting that students' attention and focus improved as a result of the intervention. However, since neither school classification nor clinician experience significantly predicting the outcome variables, alternative explanations are warranted.

There are several possible explanations for why the levels of school classification and clinician experience did not significantly predict attention and response control. First, a lack of variance in age within the college population may account for why the school classification variable was not significant. The assumption was there would be large differences in school 
maturity and development between underclassmen, upperclassmen, and graduate students; it appears this was over estimated, and that the differences in the mental makeup between the groups is roughly the same. Arain et al. (2013) asserted that the prefrontal cortex is fully developed at age 25 and is one of the last cortical regions to undergo full myelination. Using the age range provided by Arain et al. (2013), nearly all participants were experiencing some continued level of development and maturation of their prefrontal cortex, an area of the brain essential for attention, memory, learning, motor behavior, self-control and executive function. Many of the aforementioned tasks associated with the prefrontal cortex are the target of cognitive training studies. For future studies, a larger range of participant ages would be important if the variable age were to be evaluated. Another possible explanation for the lack of significant results for the school classification variable could be that the cognitive training mitigates any differences in age or maturity and brings participants to the same level of performance after training. The differences between groups may have been overcome by having a more experienced clinician help the participants with strategies which would have allowed them to adapt at their own pace over the course of the 10-week training.

Likewise, there are alternative explanations for the insignificant findings regarding the clinician experience predictor variable. Similar to the school classification predictor, an alternative explanation for the absence of significant findings could be that differences between clinicians in terms of expertise level were reduced to insignificance once clinicians were trained on the cognitive training protocol. For instance, any difference between the clinician is less impactful than their adherence to the training protocol and that their fidelity to the process is actually a more significant predictor than clinician expertise. Using this assumption, it is 
possible that a well-trained novice could facilitate similar or better participant scores than a less experienced clinician or a clinician who does not follow the protocol as advised.

When considering alternative explanations for the fourth hypothesis, an external factor like participant motivation could give some context to explain the non-significance of the predictor variables. Participant motivation in this study should be viewed through two lenses including a potential explanation for why participants enrolled in this intervention and their persistence throughout the training program. A possible explanation for this finding is that motivation may serve as an unmeasured moderator of the participant's performance. Two expectancy theories of motivation, including Vroom's Expectancy Theory (Vroom, 1964) and Mindset Theory (Dweck \& Molden, 2000), could lend a framework for potential reasons why participants opted to enroll in the intervention.

First, Vroom (1964) theorized that individuals will be motivated to put forth a high-level effort when they believe there are relationships between the effort they exert, the performance they achieve, and the outcomes and rewards they want. Vroom (1964) postulated that motivation equals valence multiplied by expectancy, which is multiplied by instrumentality. Due to the model being multiplicative, all three variables must have high positive values to attribute motivation performance choice. If either of the three variables approach zero, the likelihood of motivated performance in turn also approaches zero.

Cognitive training mirrors this equation as these programs are based on the belief that cognitive abilities can be improved by performing mental exercises (Simons et al., 2016). In this study, participants completed an initial IVA-2 CPT administration prior to the start of training. They were informed that another administration would follow with the completion of their training. Given the timing of the administrations and an explanation of the possible benefits of 
training, it is possible that participants perceived that by exerting effort during training, they would achieve the outcome of raised scores on the second administration of the IVA-2.

Therefore, the belief in a growth mindset is an asset to the participant but also a limitation of the study as a growth mindset is often present in cognitive training research (Foroughi, Monfort, Paczynski, McKnight, \& Greenwood, 2016). Furthermore, since participants self-selected into the intervention, it could be reasonably assumed that they believed their effort over the 10 -week trial would be rewarded by achieving greater focus and concentration. Thus, it is possible that participants asserted optimal effort in the cognitive training program because they desired the outcome of improved concentration. This hypothesis was supported by collateral data as measured by the high rate of attendance to sessions and willingness to pay the associated fee.

Although Vroom's theory can help make sense of why individuals may have been enticed by the cognitive training program and serve as a possible moderator of performance, other factors may have influenced the results of this study. Foroughi et al. (2016) argued that a placebo effect often influences the results of cognitive training research. They found that of 17 cognitive training studies, 11 studies advertised the potential for improvement or enhancement in their selection of participants. Further, results from the meta-analysis conducted by Au et al. (2016) showed that 17 of 19 studies overtly recruited participants. Overall, Foroughi et al. (2016) concluded that overt and suggestive selection produces positive outcomes following cognitive training. However, when comparing the findings of Foroughi et al. (2016) to the current study, the large effect sizes $(1.76,1.28$, and 1.45$)$ observed may negate possible placebo effects.

While best practices such as random selection and control groups are suggested in cognitive research (Simons et al., 2016), Boot, Simons, Stothart, and Stutts (2013) argued that 
control groups are not sufficient to rule out placebo effects. Moreover, the variability in outcomes across cognitive training research could be conceptualized through the lens of the population sampled and their expectations for results (Foroughi et al, 2016). For instance, selection methods in which advertisement of expected benefits are presented may cause a sampling bias in the form of self-selection, which could lead to an overrepresentation of participants with this belief (Boot, Blakely, \& Simons, 2011). Thus, it is possible that participants' expectations played a role in treatment outcome.

Dweck's (2000) assertion that intelligence is malleable provided a helpful lens for developing the cognitive training program used in the current study. Having a growth mindset, as detailed by Dweck (2000), was critical for the basis of this intervention, guaranteeing that the participant would engage for the entire 10 weeks of the intervention. Dweck's research has revealed that individuals have strong implicit beliefs as to whether intelligence is malleable or not. Supporting Dweck's assertion that there are group differences, research by Jaeggi et al. (2011) suggested that individuals with stronger beliefs that intelligence is malleable exhibited greater improvements in fluid intelligence tasks following cognitive training. Based on these findings, if an overrepresentation of individuals in this study believed in malleable intelligence, the measured effects of the cognitive training program may have been affected (Foroughi et al., 2016).

Considering the findings of Foroughi et al. (2016), it is likely that this study may fall into the category of overt and suggestive selection. As part of this study's selection, the cognitive training intervention was proposed with a combination of other interventions (e.g., psychotherapy, medication, neurofeedback, or no treatment) following a screening for ADHD. Information about the intervention included the time commitment, intervention activities, and 
possible outcomes. It is possible that when participants considered enrolling in this intervention, they endorsed the idea of the growth mindset. If so, this preference towards having a growth mindset would help explain why nearly all participants would continue to put forth continuous effort in the program twice a week for 10 weeks. Given the limited collateral information, it is impossible to definitively ascertain the motivations and opinions of the participants at the beginning of treatment. However, it is in my estimation that the results may mirror those found by Foroughi et al. (2016) in which selection bias impacted the results of the study.

Results from the current study offer practical implications for college students and cognitive training programs at other university counseling centers. For example, visual and auditory attention is necessary in the classroom and while completing homework assignments. Improvements in attention and response control may help students, particularly those with clinically significant attention concerns, to pay attention for a longer period in the classroom or make less mistakes due to heightened vigilance. They may also be more efficient in completing assignments due to improved processing. Increased response control could also help college students with attention concerns better adjust to their academic environment, improve grades, and have interpersonal success (Tangney, Boone, Baumeister, 2018). Thus, it is possible that participation in a cognitive training program with a coaching element could help students with significant attention concerns improve their attention and response control and ultimately, increase their academic performance.

\section{Strengths}

The foremost strength of this study is that it highlights a different method of cognitive training, in addition to exploring individual factors that could affect outcomes of attention and response control. The lack of significant results regarding the predictive variables was not 
surprising due to the exploratory nature of this study. However, given that there have been few studies that have examined cognitive training in a college population, the current study was able to provide more questions for future exploration. While Loosli, Buschkeuhl, Perrig, and Jaeggi (2012) found that cognitive training was effective among elementary students, DuPaul et al. (2009) asserted a need for interventions for college students to address attention and concentration concerns on college campuses. In the current study I sought to address this gap by examining factors that may predict the attention and concentration of college students. The hope is that this study will serve as a catalyst for additional research on cognitive training, especially studies that examine this specific cognitive training intervention with college students. Finally, a strength of this study is that a connection was established between motivation theory and the practical application of cognitive training. Extant cognitive training literature has primarily focused on the outcomes of training for near and far transfer effects. While this study also examined transfer effects, it explored possible internal mechanisms within the cognitive training intervention which could have contributed to the overall outcome of training. Of those internal mechanisms, motivation of the participant was viewed as important.

\section{Limitations}

Field (2009) stated that when examining predictor variables, multiple regression is the appropriate analysis, but he added that a theoretical rationale for the variables selected is also critical to ensure that the variables are evidence-based. The absence of a strong theoretical basis for including the predictors of college classification and experience of the clinician may have limited the findings of the present study. Results from this study were based on archival data of college students seeking mental health services during the 2014-2017 academic years at a public, land-grant institution. The use of archival data was helpful in providing uniform data collected 
over several years. However, it also led to several limitations of the study. First, the use of archival data limited how information was gathered. Participant responses to the demographics form were gathered via computer as part of a standard intake procedure. Likewise, the scores on the CPT were part of a screening process for attentional concerns. The collection of archival data was helpful in providing a standard protocol which ensured the uniformity of the data. However, by using archival data, the ability to examine other measures that could have been helpful in identifying possible confounding variables was not possible given how the information was gathered. A second major limitation of using archival data was that it did not allow for follow-up. If a different collection method was used, participants could have been approached to complete or clarify their responses. Thus, the ability to gain context about the participants' responses was potentially lost and it is possible that a small percentage of excluded cases influenced the outcome of this study.

Another limitation of using archival data in the current study is that the researcher was unable to utilize the best practice of randomly assigning independent variables. This design creates limitations in the strength of the findings (Heppner, Wampold, \& Kivlighan, 2008). The most notable weakness in this design is that it is impossible to attribute causal findings to the independent variables selected. As such, the internal validity is weakened. Although a quasiexperimental design was used to improve the likelihood of making accurate causal correlations, conclusions based upon these results should be considered while also understanding their limitations. For instance, the difference in CPT scores from pre-experiment to post-experiment were not attributed to the predictor variables but instead to alternative reasons. A potential confounding variable in the current study is the motivation of the participants given that they self-selected into the experiment and random assignment was not used. In contrast, motivation 
could also contribute to the client being more engaged in metacognition, a key component in the cognitive training protocol. Ultimately, more information needs to be gathered about how motivation of the participant positively or negatively influences the outcome of this type of cognitive training.

In addition, maturation may have been a threat to internal validity for the one group design. In a within subjects design it is difficult to determine if the changes in the dependent variable were due to the normal developmental process operating within the subject as a function of time or due to the intervention. To limit the effect of maturation, the length of training was over two to four months and training was completed within the course of a semester. Due to the relatively short time period from start to finish and the age of the participants, it is unlikely that the amplitude of the effects is due to maturation.

Lastly, given the design of the study, the findings must be viewed through their ability to be generalized to other populations and settings. For example, participants in this study were a clinical sample of students gathered from one large university counseling center. Since the participants also presented for mental health treatment, they represented a specific subset of the university population, thus limiting the generalizability of the results to other clinical populations. Likewise, with the sample being predominantly male, the effects may be different for women who participate in this cognitive training. However, it is not the intention of this cognitive training method to generalize to the entire population but rather to those individuals who present with attention and working memory concerns. This intervention has shown to be effective with college students who have attention and working memory concerns and could yield promising effects if replicated at other institutions with their students.

\section{Future Directions}


This study opens new possibilities for future research. Unlike prior cognitive training outcome studies, this study examined individual and interpersonal dynamics within training. Future studies could expand on this study by exploring other predictors such as gender, motivation, and self-reported symptoms of inattention and impulsivity. It is unknown whether the methodology used in this cognitive training yields similar results to all genders. Although recent research supports that $\mathrm{ADHD}$ does not significantly differ across genders, women tend to report lower levels of hyperactive symptoms and higher rates of anxiety and perceived mental health impairment than men (Cortese, Faraone, Bernardi, Wang, \& Blanco, 2016). The development of a gender specific protocol for cognitive training that reflects the differences of ADHD symptom expression could be helpful in advancing the effectiveness of this intervention.

Aside from studying dependent variables from a singular source (e.g., CPT), future research could also examine additional measures of attention, executive functioning, and visuospatial skills. Additionally, using measures specific to the college environment may be helpful. Lahav, Ben-Simon, Inbar-Weiss, and Katz (2018) found that the Weekly Calendar Planning Activity (WCPA-S) was an effective performance-based diagnostic tool to assess executive functioning of daily life in college students. Lahav et al. (2018) compared results of college students with ADHD to those without ADHD on the WCPA-S and found significant differences in daily executive functioning between the groups. This practical measure could assist in understanding the effects of cognitive training with a coaching component on practical aspects of a student's life, in addition to clinical functioning.

Future studies could also improve on this study by using research designs which may yield new information such as a qualitative design. Qualitative research offers rich data which may be untapped using quantitative methods. Insight gained from examining the interplay 
between cognitive training and various constructs of executive functioning may be better understood using qualitative research. Similarly, exploring cognitive training using a mixed methods design may link data found in this study to important information gathered through qualitative means, such as the participant's psychosocial and psychiatric history.

Lastly, this study highlights important clinical applications for university counseling centers. This method of cognitive training could be helpful for other university counseling centers as a way of providing a low cost and no side effect treatment option. Overall, the process of recreating this intervention would require few resources aside from the time and energy of clinician to provide the service to students. As detailed by Long (2017), a clinician at a university counseling center could feasibly recreate this experiment with a computer and working memory program, though a computer is not required. The time required (twice weekly) is marginally more than the clinical services dedicated to individual therapy or group counseling and thus, is not likely to significantly burden a clinician's clinical load at the center.

\section{Conclusion}

Since increasing numbers of students with attention concerns are enrolling in college, there is a need for new and creative clinical interventions at university counseling centers (DuPaul et al., 2009). The aim of this study was to examine the effects of a new cognitive training intervention approach with a coaching component on attention and response control, in addition to the predictive relationship between school classification and clinician experience on attention scores through a CPT. The two predictors, school classification and clinician experience, had not been explored in previous literature due to the relative uniqueness of a coaching element imbedded with a cognitive training program. It was hypothesized in the present study that participant scores across several measures of attention including global 
attention, global response control, and a unitary measure of both attention and response control would improve following a ten-week cognitive training intervention. Results from this study demonstrated greater effect sizes for the first three hypotheses than in previous studies of similar scope (Melby-Lervåg \& Hulme, 2013). An average increase of two standard deviations in prepost scores was observed for the paired sample $t$-tests, and the magnitude of these findings are unlike that of other similar studies. These differences suggested that the unique factors in this study (i.e., the presence of a clinician, the specific cognitive training protocol with an emphasis on the slave systems of working memory or a combination of factors) may have contributed to the differences in scores from pre-training to post training. It was also hypothesized that classification in school and clinician experience would significantly predict higher scores on the CPT. The findings from this dissertation did not support this hypothesis. The effect on the CPT scores for these predictors was minimal and likely due to chance alone. Discovering variables which better predict the changes in attention scores from pre-intervention to post-intervention could be improved if multiple measures of attention were used and additional information about the participants' history and clinical functioning were collected. Additionally, future studies on cognitive training could examine the mechanics of the coaching relationship between the clinician and participant and operationalize key components of the coaching method to examine whether they influence scores. Future exploration in these areas could improve current interventions and significantly contribute to the literature and clinical applications of cognitive training. 


\section{REFERENCES}

Arnett, J. J. (2000). Emerging adulthood: A theory of development from the late teens through the twenties. American Psychologist, 55(5), 469-480. doi:10.1037/0003-066x.55.5.469

Au, J., Buschkuehl, M., Duncan, G. J., \& Jaeggi, S. M. (2016). There is no convincing evidence that working memory training is NOT effective: A reply to Melby-Lervåg and Hulme (2015). Psychonomic Bulletin \& Review, 23(1), 331-337. doi: 10.3758/s13423-015-0967

Barbarito, A. J. (2016). In pursuit of science-based regulation: FDA, FTC, and the regulation of pseudoscience. Health Law Outlook, 9(1), 1-10.

Retrieved from http://scholarship.shu.edu/health-law-outlook/vol9/iss 1/3

Barkley, R. A. (1997). ADHD and the nature of self-control. New York, NY: Guilford Press.

Beck, S. J., Hanson, C. A., Puffenberger, S. S., Benninger, K. L., \& Benninger, W. B. (2010). A controlled trial of working memory training for children and adolescents with ADHD. Journal of Clinical Child \& Adolescent Psychology, 39(6), 825-836. doi: $10.1080 / 15374416.2010 .517162$

Blackwell, L. S., Trzesniewski, K. H., \& Dweck, C. S. (2007). Implicit theories of intelligence predict achievement across an adolescent transition: A longitudinal study and an intervention. Child Development, 78(1), 246-263. doi:10.1111/j.1467-8624.2007.00995.x

Borella, E., Carretti, B., Riboldi, F., \& De Beni, R. (2010). Working memory training in older adults: Evidence of transfer and maintenance effects. Psychology and Aging, 25(4), 767778. doi: $10.1037 / \mathrm{a} 0020683$

Borella, E., Carretti, B., Zanoni, G., Zavagnin, M., \& De Beni, R. (2013). Working memory training in old age: an examination of transfer and maintenance effects. Archives of clinical neuropsychology, 28(4), 331-347. doi: 10.1093/arclin/act020 
Boot, W. R., Blakely, D. P., \& Simons, D. J. (2011). Do action video games improve perception and cognition. Frontiers in Psychology, 2, 1-6. doi: 10.3389/fpsyg.2011.00226

Boot, W. R., Simons, D. J., Stothart, C., \& Stutts, C. (2013). The pervasive problem with placebos in psychology: Why active control groups are not sufficient to rule out placebo effects. Perspectives on Psychological Science, 8(4), 445-454. doi: $10.1177 / 1745691613491271$

Boswell, S. (2012). "I deserve success": Academic entitlement attitudes and their relationships with course self-efficacy, social networking, and demographic variables. Social Psychology of Education, 15, 353-365. doi:10.1007/s11218-012-9184-4

Brock, T. (2010). Young adults and higher education: Barriers and breakthroughs to success. The Future of Children, 20(1), 109-132. doi: $\underline{10707 / 333068}$

Bussing, R., Mason, D. M., Bell, L., Porter, P., \& Garvan, C. (2010). Adolescent outcomes of childhood attention-deficit/hyperactivity disorder in a diverse community sample. Journal of the American Academy of Child \& Adolescent Psychiatry, 49(6), 595605. doi: 10.1016/j.jaac.2010.03.006.

Cajal, S. R. (1894). The Croonian lecture: La fine structure des centres nerveux. Proceedings of the Royal Society of London, 55, 444-468. Retrieved from https://www.jstor.org/stable/115494

Chooi, W., \& Thompson, L. A. (2012). Working memory training does not improve intelligence in healthy young adults. Intelligence, 40, 531-542. doi: 10.1016/j.intell.2012.07.004

Clark, C. M., Lawlor-Savage, L., \& Goghari, V. M. (2017). Functional brain activation associated with working memory training and transfer. Behavioural Brain Research, 334(15), 34-49. doi: 10.1016/j.bbr.2017.07.030 
Cook, R. D. (1977). Detection of influential observation in linear regression. Technometrics, 19(1), 15-18. doi: 10.1080/00401706.1977.10489493

Cortese, S., Faraone, S. V., Bernardi, S., Wang, S., \& Blanco, C. (2016). Gender differences in adult attention-deficit/hyperactivity disorder: results from the National Epidemiologic Survey on Alcohol and Related Conditions (NESARC). The Journal of clinical psychiatry, 77(4), e421-8. doi: 10.4088/JCP.14m09630

Culpepper, L. (2011). Prevalence and impact of ADHD in college students. The Journal of Clinical Psychiatry, 72(9), e30. doi: 10.4088/JCP.11009tx1c.

Curtis, C. E., \& D’Esposito, M. (2003). Persistent activity in the prefrontal cortex during working memory. TRENDS in Cognitive Sciences, 7(9), 415-423. doi: 10.1016/S13646613(03)00197-9

DaDeppo, L. M. (2009). Integration factors related to the academic success and intent to persist of college students with learning disabilities. Learning Disabilities Research \& Practice, 24(3), 122-131. doi: 10.1111/j.1540-5826.2009.00286.x

Daneman, M., \& Carpenter, P. A. (1980). Individual differences in working memory and reading. Journal of Verbal Learning and Verbal Behavior, 19(4), 450-466. doi: $10.1016 / \mathrm{S} 0022-5371(80) 90312-6$

DeFelipe, J. (2006). Brain plasticity and mental processes: Cajal again. Neuroscience, 7(10), 811-817. doi: 10.1038/nrn2005

Diamond, A., Barnett, W. S., Thomas, J., \& Munro, S. (2007). Preschool program improves cognitive control. Science, 318(5855), 1-10. doi: 10.1126/science.1151148 
DuPaul, G. J., Weyandt, L. L., O'Dell, S. M., \& Varejao, M. (2009). College students with ADHD: Current status and future directions. Journal of Attention Disorders, 13(3), 234250. doi: $10.1177 / 1087054709340650$

Dvorsky, M. (2014). Predicting the academic functioning of college students with attentiondeficit/hyperactivity disorder: The importance of executive functions and parent report (Master's thesis). Retrieved from VCU Scholars Compass. (3498).

Dweck, C. S. (2006). Mindset: The new psychology of success. New York, NY: Random House Incorporated.

Dweck, C. S. (2015). Carol Dweck revisits the 'growth mindset'. Education Week, 35(5), 20-24.

Dweck, C. S., \& Leggett, E. L. (1988). A social-cognitive approach to motivation and personality. Psychological Review, 95(2), 256-273. doi:10.1037/0033-295X.95.2.256

Faul, F., Erdfelder, E., Buchner, A., \& Lang, A. G. (2009). Statistical power analyses using G* Power 3.1: Tests for correlation and regression analyses. Behavior Research Methods, 41(4), 1149-1160. doi: 10.3758/BRM.41.4.1149.

Field, A. (2009). Discovering statistics using SPSS. Sage publications.

Fisher, R. (1998). Thinking about thinking: Developing metacognition in children. Early Child Development and Care, 141(1), 1-15. doi: 10.1080/0300443981410101

Flory, K., Payne, R. A., \& Benson, K. (2014). Misuse of prescription stimulant medication among college students: Summary of the research literature and clinical recommendations. Journal of Clinical Outcomes Management, 21(12), 50-76. doi: 10.1007/s10567-014-0177-z 
Foroughi, C. K., Monfort, S. S., Paczynski, M., McKnight, P. E., \& Greenwood, P. M. (2016). Placebo effects in cognitive training. Proceedings of the national Academy of Sciences, 201601243. doi: 10.1073/pnas.1601243113

Fukuda, K., \& Vogel, E. K. (2009). Human variation in overriding attentional capture. The Journal of Neuroscience, 29(27), 8726-8733. doi: 10.1523/NEUROSCI.2145-09.2009

Gazzaley, A., \& D'Esposito, M. (2007). Top-down modulation and normal aging. Annas of the New York Academy of Sciences, 1097, 67-83. doi: 10.1196/annals.1379.010

Gold, N. J. (2015). Family distress, first-generation college status, and financial stress as predictors of alcohol use in college students seeking mental health treatment (Doctoral dissertation). Retrieved from Proquest. (3718455).

Goldberg, S. B., Rousmaniere, T., Miller, S. D., Whipple, J., Nielsen, S. L., Hoyt, W. T., \& Wampold, B. E. (2016). Do psychotherapists improve with time and experience? A longitudinal analysis of outcomes in a clinical setting. Journal of Counseling Psychology, 63(1), 1. doi: 10.1037/cou0000131

Grant, H., \& Dweck, C. S. (2003). Clarifying achievement goals and their impact. Journal of Personality and Social Psychology, 85(3), 541-553. doi: 10.1037/0022-3514.85.3.541

Green, A. L., \& Rabiner, D. L. (2012). What do we really know about ADHD in college students? Neurotherapeutics, 9(3), 559-568. doi:10.1007/s13311-012-0127-8

Gropper, R. J., Gotlieb, H., Kronitz, R., \& Tannock, R. (2014). Working memory training in college students with ADHD or LD. Journal of Attention Disorders, 18(4), 331-345. doi: $10.1177 / 1087054713516490$

Gudjonsson, G. H., Sigurdsson, J. F., Smari, J., \& Young, S. (2009). The relationship between satisfaction with life, ADHD symptoms, and associated problems among university 
students. Journal of Attention Disorders, 12(6), 507-515.

doi:10.1177/1087054708323018

Gutman, L. M., \& Schoon, I. (2013). The impact of non-cognitive skills on outcomes for young people [PDF]. Retrieved from https://educationendowmentfoundation.org.uk/public/files/Publications/EEF_Lit_Review _Non-CognitiveSkills.pdf

Hambrick, D. Z. (2014). Brain training doesn't make you smarter: Scientists doubt claims from brain training companies [Webpage]. Retrieved from: https://www.scientificamerican.com/article/brain-training-doesn-t-make-you-smarter/

Hart, V., Blattner, J., \& Leipsic, S. (2001). Coaching versus therapy: A perspective. Consulting Psychology Journal: Practice and Research, 53(4), 229. doi: 10.1037//10614087.53.4.229

Harrison, T. L., Shipstead, Z., Hicks, K. L., Hambrick, D. Z., Redick, T. S., \& Engle, R. W. (2013). Working memory training may increase working memory capacity but not fluid intelligence. Psychological Science, 24(12), 2409-2419. doi: 10.1177/0956797613492984

Hatano, G., \& Inagaki, K. (1986). Two courses of expertise. In H. W. Stevenson, H. Azuma, \& K. Hakuta (Eds.), A series of books in psychology: Child development and education in Japan (pp. 262-272). New York: W H Freeman/Times Books/ Henry Holt \& Co.

Heppner, P. P., Kivlighan, D. M., Jr., \& Wampold, B. E. (1999). Research design in counseling ( $2^{\text {nd }}$ ed.). Belmont, CA: Wadsworth.

Heppner, P. P., Wampold, B. E., \& Kivlighan, D. M., (2008). Research design in counseling (3rd ed.). Belmont, CA: Thomson Higher Education 
Hertzog, C., Kramer, A. F., Wilson, R. S., \& Lindenberger, U. (2008). Enrichment effects on adult cognitive development: Can the functional capacity of older adults be preserved and enhanced? Psychological Science in the Public Interest, 9(1), 1-65. doi: 10.1111/j.15396053.2009.01034.x

Holman, C., \& de Villers-Sidani, E. (2014). Indestructible plastic: The neuroscience of the new aging brain. Frontiers in Human Neuroscience, 8, 1-15. doi: 10.3389/fnhum.2014.00219

Holmes, J., Gathercole, S. E., Place, M., Dunning, D. L., Hilton, K. A., \& Elliott, J. G. (2010). Working memory deficits can be overcome: Impacts of training and medication on working memory in children with ADHD. Applied Cognitive Psychology, 24(6), 827-836. doi: 10.1002/acp.1589

Hong, Y. Y., Chiu, C. Y., Dweck, C. S., Lin, D. M. S., \& Wan, W. (1999). Implicit theories, attributions, and coping: A meaning system approach. Journal of Personality and Social Psychology, 77(3), 588-599. doi: 10.1037\%2F0022-3514.77.3.5

Horowitz-Kraus, T., \& Breznitz, Z. (2009). Can the error detection mechanism benefit from training the working memory? A comparison between dyslexics and controls_—an ERP study. PloS one, 4(9), e7141. doi: 10.1371/journal.pone.0007141

Hurley, D. (2013, April). New studies show promise for brain training in improving fluid intelligence [Webpage]. Retrieved from: https://www.theatlantic.com/health/archive/2014/04/new-studies-show-promise-forbrain-training-in-improving-fluid-intelligence/360290/

IBM Corp. Released 2017. IBM SPSS Statistics for Windows, Version 25.0. Armonk, NY: IBM Corp. 
Jaeggi, S. M., Buschkuehl, M., Jonides, J., \& Perrig, W. J. (2008). Improving fluid intelligence with training on working memory. Proceedings of the National Academy of Sciences, 105(19), 6829-6833. doi: 10.1073/pnas.0801268105

Jaeggi, S. M., Buschkuehl, M., Jonides, J., \& Shah, P. (2011). Short- and long-term benefits of cognitive training. Proceedings of the National Academy of Sciences, 108(25), 1008110086. doi: 10.1073/pnas.1103228108

Jaeggi, S. M., Studer-Luethi, B., Buschkuehl, M., Su, Y. F., Jonides, J., \& Perrig, W. J. (2010). The relationship between n-back performance and matrix reasoning: Implications for training and transfer. Intelligence, 38(6), 625-635. doi: 10.1016/j.intell.2010.09.001

Jairam, D. (2014). The effects of cognitive training on academic self-efficacy in college students. International Journal of Sciences: Basic Applied Research, 15(2), 126-139.

Johnson, S. B., Blum, R. W., \& Giedd, J. N. (2009). Adolescent maturity and the brain: The promise and pitfalls of neuroscience research in adolescent health policy. Journal of Adolescent Health, 45(3), 216-221. doi: 10.1016/j.jadohealth.2009.05.016

Jones, S., Nyberg, L., Sandblom, J., Neely, A. S., Ingvar, M., Petersson, K. M., \& Bäckman, L. (2006). Cognitive and neural plasticity in aging: general and task-specific limitations. Neuroscience \& Biobehavioral Reviews, 30(6), 864-871. doi: 10.1016/j.neubiorev.2006.06.012

Kable, J. W., Caulfield, M. K., Falcone, M., McConnell, M., Bernardo, L., Parthasarathi, T., ... \& Diefenbach, P. (2017). No effect of commercial cognitive training on brain activity, choice behavior, or cognitive performance. Journal of Neuroscience, 37(31), 7390-7402. doi: 10.1523/JNEUROSCI.2832-16.2017 
Katsuki, F., \& Constantinidis, C. (2013). Bottom-up and top-down attention. The Neuroscientist, 20(5), 509-521. doi: 10.1177/1073858413514136

King, P. M., \& Kitchener, K. S. (1994). Developing Reflective Judgment: Understanding and Promoting Intellectual Growth and Critical Thinking in Adolescents and Adults. JosseyBass Higher and Adult Education Series and Jossey-Bass Social and Behavioral Science Series. Jossey-Bass, 350 Sansome Street, San Francisco, CA 94104-1310.

Kirchner, W. K. (1958). Age differences in short-term retention of rapidly changing information. Journal of Experimental Psychology, 55(4), 352-358. doi: 10.1037/h0043688

Knafo, S., \& Venero, C. (Eds.). (2014). Cognitive enhancement: Pharmacologic, environmental and genetic factors. San Diego, CA: Academic Press.

Kramer, A. F., Bherer, L., Colcombe, S. J., Dong, W., \& Greenough, W. T. (2004). Environmental influences on cognitive and brain plasticity during aging. The Journals of Gerontology Series A: Biological Sciences and Medical Sciences, 59(9), M940-M957.

Lahav, O., Ben-Simon, A., Inbar-Weiss, N., \& Katz, N. (2018). Weekly calendar planning activity for university students: comparison of individuals with and without ADHD by gender. Journal of attention disorders, 22(4), 368-378. doi:10.1177/1087054714564621

Li, H., Li, J., Li, N., Li, B., Wang, P., \& Zhou, T. (2011). Cognitive intervention for persons with mild cognitive impairment: A meta-analysis. Ageing Research Reviews, 10(2), 285-296. doi: 10.1016/j.arr.2010.11.003

Liakoni, E., Schaub, M. P., Maier, L. J., Glauser, G. V., \& Liechti, M. E. (2015). The use of prescription drugs, recreational drugs, and "soft enhancers" for cognitive enhancement among swiss secondary school students. PLoS One, 10(10), 1-12. doi:

10.1371/journal.pone.0141289 
Long, D.G., II. (2017). Cognitive component analysis \& training (CCAT): A primer on a new approach to cognitive training. (Unpublished work). West Virginia University, WV.

Loosli, S. V., Buschkuehl, M., Perrig, W. J., \& Jaeggi, S. M. (2012). Working memory training improves reading processes in typically developing children. Child Neuropsychology, 18(1), 62-78. doi: 10.1080/09297049.2011.575772

Markham, J. A., \& Greenough, W. T. (2004). Experience-driven brain plasticity: Beyond the synapse. Neuron Glia Biology, 1(4), 351-363. doi: 10.1017/s1740925x05000219

Mawjee, K., Woltering, S., \& Tannock, R. (2015). Working memory training in post-secondary students with ADHD: A randomized controlled study. PLOS One, 10(9), 1-21. doi: 10.1371/journal.pone.0137173

Mason, M. J. (2009). Rogers redux: Relevance and outcomes of motivational interviewing across behavioral problems. Journal of Counseling \& Development, 87(3), 357362.doi:10.1002/j.1556-6678.2009.tb00117.x

McCabe, D. P., Roediger III, H. L., McDaniel, M. A., Balota, D. A., \& Hambrick, D. Z. (2010). The relationship between working memory capacity and executive functioning: Evidence for a common executive attention construct. Neuropsychology, 24(2), 222-243. doi: $10.1037 / \mathrm{a} 0017619$

Melby-Lervåg, M., \& Hulme, C. (2013). Is working memory training effective? A meta-analytic review. Developmental Psychology, 49(2), 270-291. doi: 10.1037/a0028228

Mercado III, E. (2008). Neural and cognitive plasticity: From maps to minds. Psychological Bulletin, 134(1), 109. doi: 10.1037/0033-2909.134.1.109

Miller, S. D., Hubble, M. A., Chow, D. L., \& Seidel, J. A. (2013). The outcome of psychotherapy: Yesterday, today, and tomorrow. doi: 10.1037/a0031097 
Miller, W. R., \& Rollnick, S. (2013). Motivational interviewing: Helping people change (3 ${ }^{\text {rd }}$ Ed.). New York, NY: Guilford Press.

Nagaoka, J., Farrington, C. A., Roderick, M., Allensworth, E., Keyes, T. S., Johnson, D. W., \& Beechum, N. O. (2013). Readiness for college: The role of noncognitive factors and context. Voices in Urban Education, 38, 45-52.

Noack, H., Lövdén, M., \& Schmiedek, F. (2014). On the validity and generality of transfer effects in cognitive training research. Psychological research, 78(6), 773-789. doi: $10.1007 / \mathrm{s} 00426-014-0564-6$

Norcross, J. C., Krebs, P. M., \& Prochaska, J. O. (2011). Stages of change. Journal of Clinical Psychology, 67(2), 143-154. doi: 10.1002/jclp.20758

Norén Selinus, E., Molero, Y., Lichtenstein, P., Anckarsäter, H., Lundström, S., Bottai, M., \& Hellner Gumpert, C. (2013). Subthreshold and threshold attention deficit hyperactivity disorder symptoms in childhood: Psychosocial outcomes in adolescence in boys and girls. Acta Psychiatrica Scandinavica, 134(6), 533-545. doi: 10.1111/acps.12655

Paas, F., Renkl, A., \& Sweller, J. (2013). Cognitive load theory and instructional design: Recent developments. Educational Psychologist, 38(1), 1-4. doi: 10.1207/S15326985EP3801_1

Parker, J., Wales, G., Chalhoub, N., \& Harpin, V. (2013). The long-term outcomes of interventions for the management of attention-deficit hyperactivity disorder in children and adolescents: A systematic review of randomized controlled trials. Psychology Research and Behavior Management, 6, 87-99. doi: 10.2147/PRBM.S49114

Peelen, M. V., Heslenfeld, D. J., \& Theeuwes, J. (2004). Endogenous and exogenous attention shifts are mediated by the same large-scale neural network. Neuroimage, 22(2), 822-830. doi: 10.1016/j.neuroimage.2004.01.044 
Penadés, R., Catalán, R., Salamero, M., Boget, T., Puig, O., Guarch, J., \& Gastó, C. (2006). Cognitive remediation therapy for outpatients with chronic schizophrenia: a controlled and randomized study. Schizophrenia research, 87(1-3), 323-331. doi: 10.1016/j.schres.2006.04.019

Peng, P., Miller., A. C (2016). "Does attention training work? A selective meta-analysis to explore the effects of attention training and moderators." Learning and Individual Differences, 45, 77-87. doi: 10.1016/j.lindif.2015.11.012

Quinn, C. A. (2003). Detection of malingering in assessment of adult ADHD. Archives of Clinical Neuropsychology, 18(4), 379-395. doi: 10.1016/S0887-6177(02)00150-6

Rapport, M. D., Orban, S. A., Kofler, M. J., \& Friedman, L. M. (2013). Do programs designed to train working memory, other executive functions, and attention benefit children with ADHD? A meta-analytic review of cognitive, academic, and behavioral outcomes. Clinical Psychology Review, 33(8), 1237-1252. doi: 10.1016/j.cpr.2013.08.005

Richmond, L. L., Morrison, A. B., Chein, J. M., \& Olson, I. R. (2011). Working memory training and transfer in older adults. Psychology and aging, 26(4), 813. doi: 10.1037/a0023631

Roche, J. D., \& Johnson, B. D. (2014). Cogmed working memory training product review. Journal of Attention Disorders, 18(4), 379-384. doi: 10.117/1087054714524275

Sandford, J. A., \& Turner, A. (1995). Intermediate visual and auditory continuous performance test interpretation manual. Richmond, VA: Braintrain.

Salminen, T., Strobach, T., \& Schubert, T. (2012). On the impacts of working memory training on executive functioning. Frontiers in human neuroscience, 6, 166. doi:10.3389/fnhum.2012.00166 
Savin, N. E., \& White, K. J. (1977). The Durbin-Watson test for serial correlation with extreme sample sizes or many regressors. Econometrica: Journal of the Econometric Society, 1989-1996. doi: $10.2307 / 1914122$

Seckler, P., Burns, D., Montgomery, L., \& Sandford, J. A. (1995). A reliability study of IVA: Intermediate visual and auditory continuous performance test. Poster session presented at the Annual Convention of Ch. A. D. D., Washington, DC.

Shipstead, Z., Redick, T. S., \& Engle, R. W. (2013). Is working memory training effective? Psychological Bulletin, 138(4), 628-654. doi: 10.1037/a0027473

Shiran, A., \& Breznitz, Z. (2011). The effect of cognitive training on recall range and speed of information processing in the working memory of dyslexic and skilled readers. Journal of Neurolinguistics, 24, 524-537. doi: 10.1016/j.neuroling.2010.12.001

Simons, D. J., Boot, W. R., Charness, N., Gathercole, S. E., Chabris, C. F., Hambrick, D. Z., \& Stine-Morrow, E. A. (2016). Do "brain-training” programs work? Psychological Science in the Public Interest, 17(3), 103-186. doi: 10.1177/1529100616661983

Stephenson, C. L., \& Halpern, D. F. (2013). Improved matrix reasoning is limited to training on tasks with visuospatial component. Intelligence, 41, 341-357. doi:

10.1016/j.intell.2013.05.006

Strange, C. C., \& King, P. M. (1981). Intellectual development and its relationship to maturation during the college years. Journal of Applied Developmental Psychology, 2(4), 281-295. doi: 10.1016/0193-3973(81)90017-4

Tangney, J. P., Boone, A. L., \& Baumeister, R. F. (2018). High self-control predicts good adjustment, less pathology, better grades, and interpersonal success. In Self-Regulation and Self-Control (pp. 181-220). Routledge. 
Tanji, J., \& Hoshi, E. (2008). Role of the lateral prefrontal cortex in executive behavioral control. Physiological Reviews, 88(1), 37-57. doi: 10.1152/physrev.00014.2007

Tanner, K. D. (2012). Promoting student metacognition. CBE-Life Sciences Education, 11(2), 113-120. doi: 10.1187/cbe.12-03-0033

Thompson, T. W., Waskom, M. L., Garel, K. L. A., Cardenas-Iniguez, C., Reynolds, G. O., Winter, R., ... \& Gabrieli, J. D. (2013). Failure of working memory training to enhance cognition or intelligence. PloS One, 8(5), 1-15. doi: 10.1371/journal.pone.0063614

Turgut, M., Yurttas, C., \& Tubbs, R. S. (2018). Island of Reil (insula) in the human brain: Anatomical, functional, clinical and surgical aspects. Switzerland: Springer International Publishing AG.

U.S. Department of Education. (2012). Digest of Education Statistics. Institute of Education Sciences National Center for Education Statistics. Retrieved from: http://nces.ed.gov/programs/digest/d11/tables/dt11_353.asp

Volkow, N. D., Wang, G. J., Newcorn, J. H., Kollins, S. H., Wigal, T. L., Telang, F., ... \& Wong, C. (2011). Motivation deficit in ADHD is associated with dysfunction of the dopamine reward pathway. Molecular psychiatry, 16(11), 1147. doi: 10.1038/mp.2010.97

Vroom, V.H. (1964). Work and motivation. Oxford, England: Wiley.

Vygotsky, L. (1978). Interaction between learning and development. In M. Gauvain \& M. Cole (Eds.), Readings on the development of children (pp. 29-36). New York: W.H. Freeman and Company

Willis, S. L., \& Schaie, K. W. (2009). Cognitive training and plasticity: theoretical perspective and methodological consequences. Restorative neurology and neuroscience, 27(5), 375389. doi: $10.3233 / \mathrm{RNN}-2009-0527$ 
Wykes, T., Reeder, C., Williams, C., Corner, J., Rice, C., \& Everitt, B. (2003). Are the effects of cognitive remediation therapy (CRT) durable? Results from an exploratory trial in schizophrenia. Schizophrenia research, 61(2-3), 163-174. doi: 10.1016/S09209964(02)00239-6

Wampold, B. E. (2015). How important are the common factors in psychotherapy? An update. World Psychiatry, 14(3), 270-277. doi: 10.1002/wps.20238

Zokaei, N., MacKellar, C., Čepukaitytè, G., Patai, E. Z., \& Nobre, A. C. (2017). Cognitive training in the elderly: bottlenecks and new avenues. Journal of cognitive neuroscience, 29(9), 1473-1482.doi: 10.1162/jocn_a_01080 
APPENDIX A: IRB APPROVAL

\section{WestVirginiaUniversity.}

Office of Resenrch Integrity and Complinnee

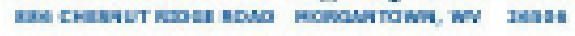

\section{Acknowledgement of Eremption}

$0605 / 2018$

To: Manica Leppma

From: WVU Office of Research Integrity of Compliance

Protocol Type: Exempt

Approwal Date: 0605/2018

Submission Type: Initial

Expiration Date: 0604/2021

Funding N/A

WVU Protocol \#: 1804090908

Protocol Title: Efficacy of Cognitive Training Intervention with a Coaching Component on Aftention and Response Control in Emerging Adults

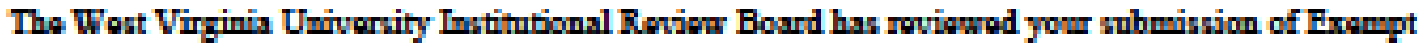
Frotocol 180409090 . Additional detnils regaring the rwiow are bolow:

- This rwarch stady was granted an axsmption in accordance with Resourch on wisting data, documonts, records, pathologiral spocimans, or diagnostic apocimeme [45 CFR 46.101(4)] In accordance with the Hoalth Inmance Portability and Aceountability Act, a wainer of rwarch authorization has benn granted. Plose fulfill the subject acconnting requirsmonts ansociatod with the granting of this raver. All oxomptions are only good for thres yours. If this reaseh oxtonds more than throe ywan byond the approved datn, thon the ronourchar will have to requant another oxamption. The folloning documonts have bon acknowledged for we in this stmity and are avilable in the WVUthe rystem:

The following docmmants wore roviowod and approwed for use as part of this anturission. Only the documents listed below may be wad in the resarch. Plase access and print the filos in the Noten $s$ Athchments saction of your appooved protocol.

- HIPAa Waiver Form CF.pdf

- Variablon to amalyodpdf 
WVU IRB acknowledgement of protocol 180409008 will expire on 06042021.

If the stady in to continse beyoud the orpiration date, a renowal application must be submitted no later than two (2) woeks prior to expiration date. It is your re ponsibility to mbeit your protocol for reneral

Once you bugin your bman mbjocts rownch, the follewing rogulations apply:

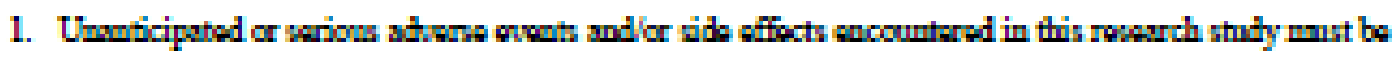
repouted to the IRB within five (0) dyn, using the Notify IFB sction in the olectranic protocol.

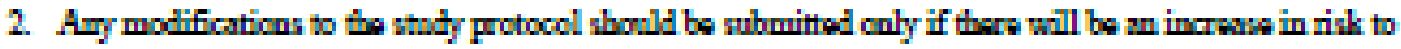
rubject accourpuning the proposed change(b).

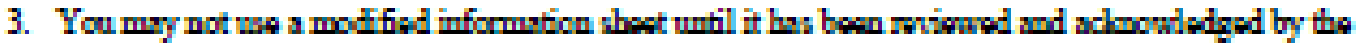
WVU IRB prior to implamoutation.

The Office of Ranouch Integrity and Conpliance will be glad to provide anistance to you throughout the ronourch procons. Plose feal fres to contact a by phone, at 304.293 .7073 or by amvil at

IRBinmail.ovu odu

Sinceraly.

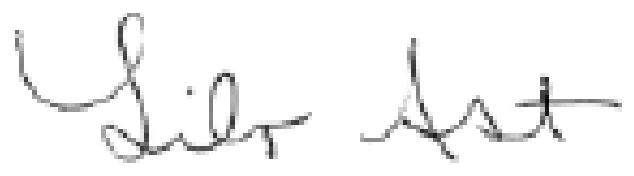

Uh 4 की

ins Adrititries 
APPENDIX B: STUDENT DEMOGRAPHIC SURVEY (SDS)

\begin{tabular}{|c|c|}
\hline Question Text & Answers \\
\hline Attended counseling for mental health concerns & $\begin{array}{l}\text { Never } \\
\text { Prior to college } \\
\text { After starting college } \\
\text { Both }\end{array}$ \\
\hline $\begin{array}{l}\text { Taken prescribed medication for mental health } \\
\text { concerns }\end{array}$ & $\begin{array}{l}\text { Never } \\
\text { Prior to college } \\
\text { After starting college } \\
\text { Both }\end{array}$ \\
\hline \multirow[t]{2}{*}{ Been hospitalized for mental health concerns } & $\begin{array}{l}\text { Answer Set A: How many times } \\
\text { Never } \\
1 \text { time } \\
2-3 \text { times } \\
4-5 \text { times } \\
\text { More than } 5 \text { times }\end{array}$ \\
\hline & $\begin{array}{l}\text { Answer Set B: The Last Time } \\
\text { Never } \\
\text { Within the last } 2 \text { weeks } \\
\text { Within the last month } \\
\text { Within the last year } \\
\text { Within the last } 1-5 \text { years } \\
\text { More than } 5 \text { years ago }\end{array}$ \\
\hline Felt the need to reduce your alcohol or drug use & $\begin{array}{l}\text { Answer Set A: How many Times } \\
\text { Answer Set B: The Last Time }\end{array}$ \\
\hline $\begin{array}{l}\text { Others have expressed concern about your alcohol } \\
\text { or drug use }\end{array}$ & $\begin{array}{l}\text { Answer Set A: How many Times } \\
\text { Answer Set B: The Last Time }\end{array}$ \\
\hline Received treatment for alcohol or drug use & $\begin{array}{l}\text { Answer Set A: How many Times } \\
\text { Answer Set B: The Last Time }\end{array}$ \\
\hline $\begin{array}{l}\text { Purposely injured yourself without suicidal intent } \\
\text { (e.g., cutting, hitting, burning etc.) }\end{array}$ & $\begin{array}{l}\text { Answer Set A: How many Times } \\
\text { Answer Set B: The Last Time }\end{array}$ \\
\hline Seriously considered attempting suicide & $\begin{array}{l}\text { Answer Set A: How many Times } \\
\text { Answer Set B: The Last Time }\end{array}$ \\
\hline Made a suicide attempt & $\begin{array}{l}\text { Answer Set A: How many Times } \\
\text { Answer Set B: The Last Time }\end{array}$ \\
\hline
\end{tabular}




\begin{tabular}{|c|c|}
\hline $\begin{array}{l}\text { Considered causing serious physical injury to } \\
\text { another person }\end{array}$ & $\begin{array}{l}\text { Answer Set A: How many Times } \\
\text { Answer Set B: The Last Time }\end{array}$ \\
\hline Intentionally caused serious physical pain to another & $\begin{array}{l}\text { Answer Set A: How many Times } \\
\text { Answer Set B: The Last Time }\end{array}$ \\
\hline $\begin{array}{l}\text { Someone had sexual contact with you without your } \\
\text { consent (e.g., you were afraid to stop what was } \\
\text { happening, passed out, drugged, drunk, } \\
\text { incapacitated, asleep, threatened or physically } \\
\text { forced) }\end{array}$ & $\begin{array}{l}\text { Answer Set A: How many Times } \\
\text { Answer Set B: The Last Time }\end{array}$ \\
\hline $\begin{array}{l}\text { Experienced harassing, controlling, and/or abusive } \\
\text { behavior from another person (e.g., friend, family } \\
\text { member, partner, or authority figure) }\end{array}$ & $\begin{array}{l}\text { Answer Set A: How many Times } \\
\text { Answer Set B: The Last Time }\end{array}$ \\
\hline $\begin{array}{l}\text { Experienced a traumatic event that caused you to } \\
\text { feel intense fear, helplessness, or horror }\end{array}$ & $\begin{array}{l}\text { Answer Set A: How many Times } \\
\text { Answer Set B: The Last Time }\end{array}$ \\
\hline $\begin{array}{l}\text { If you selected, "yes" for the previous question, } \\
\text { please briefly describe the event(s): }\end{array}$ & Free Response \\
\hline $\begin{array}{l}\text { Please select the traumatic event(s) you have } \\
\text { experienced }\end{array}$ & $\begin{array}{l}\text { Childhood physical abuse } \\
\text { Childhood sexual abuse } \\
\text { Childhood emotional abuse } \\
\text { Physical attack (e.g., mugged, } \\
\text { beaten up, shot, stabbed, } \\
\text { threatened with weapon) } \\
\text { Sexual violence (rape or attempted } \\
\text { rape, sexually assaulted, stalked, } \\
\text { abused by intimate partner, etc.) } \\
\text { Military combat or war zone } \\
\text { experiences Kidnapped or taken } \\
\text { hostage } \\
\text { Serious accident, fire, or explosion } \\
\text { (e.g., an industrial, farm, car, } \\
\text { plane, or boating accident) } \\
\text { Terrorist attack Near drowning } \\
\text { Diagnosed with life threatening } \\
\text { illness Natural disaster (e.g., flood, } \\
\text { quake, hurricane, etc.) } \\
\text { Imprisonment or Torture Animal } \\
\text { attack Other (please specify) }\end{array}$ \\
\hline Other traumatic event & Free response \\
\hline
\end{tabular}




\begin{tabular}{|c|c|}
\hline $\begin{array}{l}\text { Think back over the last two weeks. How many } \\
\text { times have you had: five or more drinks* in a row } \\
\text { (for males) OR four or more drinks* in a row (for } \\
\text { females)? }\end{array}$ & $\begin{array}{l}\text { None } \\
\text { Once } \\
\text { Twice } \\
3 \text { to } 5 \text { times } \\
6 \text { to } 9 \text { times } \\
10 \text { or more times }\end{array}$ \\
\hline $\begin{array}{l}\text { Think back over the last two weeks. How many } \\
\text { times have you smoked marijuana? }\end{array}$ & $\begin{array}{l}\text { None } \\
\text { Once } \\
\text { Twice } \\
3 \text { to } 5 \text { times } \\
6 \text { to } 9 \text { times } \\
10 \text { or more times }\end{array}$ \\
\hline $\begin{array}{l}\text { Are you registered with the office of disability } \\
\text { services on this campus, as having a documented } \\
\text { and diagnosed disability? }\end{array}$ & $\begin{array}{l}\text { Yes } \\
\text { No }\end{array}$ \\
\hline $\begin{array}{l}\text { If you selected, "yes" for the previous question, } \\
\text { please indicate which category of disability you are } \\
\text { registered for (check all that apply): }\end{array}$ & $\begin{array}{l}\text { Attention Deficit/Hyperactivity } \\
\text { Disorders } \\
\text { Deaf or Hard of Hearing } \\
\text { Learning Disorders } \\
\text { Mobility Impairments } \\
\text { Neurological Disorders } \\
\text { Physical/health related Disorders } \\
\text { Psychological Disorder/Condition } \\
\text { Visual Impairments } \\
\text { Other (please specify) }\end{array}$ \\
\hline Other disability: & Free response \\
\hline $\begin{array}{l}\text { Please indicate how much you agree with this } \\
\text { statement: "I get the emotional help and support I } \\
\text { need from my family." }\end{array}$ & $\begin{array}{l}\text { Strongly disagree } \\
\text { Somewhat disagree } \\
\text { Neutral } \\
\text { Somewhat agree } \\
\text { Strongly agree }\end{array}$ \\
\hline $\begin{array}{l}\text { Please indicate how much you agree with this } \\
\text { statement: "I get the emotional help and support I } \\
\text { need from my social network (e.g., friends \& } \\
\text { acquaintances)." }\end{array}$ & $\begin{array}{l}\text { Strongly disagree } \\
\text { Somewhat disagree } \\
\text { Neutral } \\
\text { Somewhat agree } \\
\text { Strongly agree }\end{array}$ \\
\hline Client ID & $\begin{array}{l}\text { Automatically generated by } \\
\text { Titanium during upload of de-identified } \\
\text { data. }\end{array}$ \\
\hline
\end{tabular}




\begin{tabular}{|c|c|}
\hline Age (in years) & $\begin{array}{l}\text { Automatically generated by Titanium } \\
\text { during the upload of deidentified data } \\
\text { from the date of birth stored in the } \\
\text { client record. }\end{array}$ \\
\hline What is your gender identity? & $\begin{array}{l}\text { Woman } \\
\text { Man } \\
\text { Transgender } \\
\text { Self-identify (please specify) }\end{array}$ \\
\hline Self-identify gender identity & Free response \\
\hline What was your sex at birth? & $\begin{array}{l}\text { Female } \\
\text { Male } \\
\text { Intersex }\end{array}$ \\
\hline Do you consider yourself to be: & $\begin{array}{l}\text { Heterosexual } \\
\text { Lesbian } \\
\text { Gay } \\
\text { Bisexual } \\
\text { Questioning } \\
\text { Self-identify (please specify) }\end{array}$ \\
\hline Self-identify sexual orientation & Free response \\
\hline $\begin{array}{l}\text { Since puberty, with whom have you had sexual } \\
\text { experience(s)? }\end{array}$ & $\begin{array}{l}\text { Only with men } \\
\text { Mostly with men } \\
\text { About the same number of men and } \\
\text { women Mostly with women } \\
\text { Only with women } \\
\text { I have not had sexual experiences }\end{array}$ \\
\hline $\begin{array}{l}\text { People are different in their sexual attraction to other } \\
\text { people. Which best describes your current feelings? } \\
\text { Are you: }\end{array}$ & $\begin{array}{l}\text { Only attracted to women } \\
\text { Mostly attracted to women } \\
\text { Equally attracted to women and } \\
\text { men } \\
\text { Mostly attracted to men } \\
\text { Only attracted to men } \\
\text { Not sure }\end{array}$ \\
\hline What is your race/ethnicity? & $\begin{array}{l}\text { African American / Black } \\
\text { American Indian or Alaskan } \\
\text { Native Asian American / Asian } \\
\text { Hispanic / Latino/a } \\
\text { Native Hawaiian or Pacific } \\
\text { Islander Multi-racial }\end{array}$ \\
\hline
\end{tabular}




\begin{tabular}{|c|c|}
\hline & $\begin{array}{l}\text { White } \\
\text { Self-identify (please specify) }\end{array}$ \\
\hline Self-identify race/ethnicity & Free Response \\
\hline $\begin{array}{l}\text { If you would like to, please further describe your } \\
\text { racial, cultural, ethnic, or regional identity: }\end{array}$ & Free Response \\
\hline What is your country of origin? & Drop Down menu of all countries \\
\hline Are you an international student? & $\begin{array}{l}\text { Yes } \\
\text { No }\end{array}$ \\
\hline Relationship status: & $\begin{array}{l}\text { Single } \\
\text { Serious dating or committed } \\
\text { relationship } \\
\text { Civil union, domestic partnership, } \\
\text { or equivalent } \\
\text { Married } \\
\text { Separated } \\
\text { Divorced } \\
\text { Widowed }\end{array}$ \\
\hline Religious or spiritual preference: & $\begin{array}{l}\text { Agnostic } \\
\text { Atheist } \\
\text { Buddhist } \\
\text { Catholic } \\
\text { Christian } \\
\text { Hindu } \\
\text { Jewish } \\
\text { Muslim } \\
\text { No preference } \\
\text { Self-identify (please specify) }\end{array}$ \\
\hline Other religious or spiritual preference: & Free response \\
\hline $\begin{array}{l}\text { To what extent does your religious or spiritual } \\
\text { preference play an important role in your life? }\end{array}$ & $\begin{array}{l}\text { Very important } \\
\text { Important } \\
\text { Neutral } \\
\text { Unimportant } \\
\text { Very unimportant }\end{array}$ \\
\hline Current academic status: & $\begin{array}{l}\text { Freshman / First-year } \\
\text { Sophomore } \\
\text { Junior } \\
\text { Senior } \\
\text { Graduate / professional degree }\end{array}$ \\
\hline
\end{tabular}




\begin{tabular}{|c|c|}
\hline & $\begin{array}{l}\text { student } \\
\text { Non-student } \\
\text { High-school student taking } \\
\text { college classes } \\
\text { Non-degree student } \\
\text { Faculty or staff } \\
\text { Other (please specify) }\end{array}$ \\
\hline Other academic status: & Free Response \\
\hline Graduate or professional degree program: & $\begin{array}{l}\text { Post-Baccalaureate } \\
\text { Masters } \\
\text { Doctoral degree } \\
\text { Law } \\
\text { Medical } \\
\text { Pharmacy } \\
\text { Dental } \\
\text { Veterinary Medicine } \\
\text { Not Applicable } \\
\text { Other (please specify) }\end{array}$ \\
\hline Other graduate or professional degree type: & Free Response \\
\hline $\begin{array}{l}\text { What year are you in your graduate/professional } \\
\text { program? }\end{array}$ & 1-5 (drop-down list) \\
\hline What kind of housing do you currently have? & $\begin{array}{l}\text { On-campus residence } \\
\text { hall/apartment } \\
\text { On/off campus fraternity/sorority } \\
\text { house } \\
\text { On/off campus co-operative house } \\
\text { Off-campus apartment/house } \\
\text { Other (please specify) }\end{array}$ \\
\hline Other housing: & Free Response \\
\hline With whom do you live? (check all that apply) & $\begin{array}{l}\text { Alone } \\
\text { Spouse, partner, or significant } \\
\text { other Roommate(s) } \\
\text { Children } \\
\text { Parent(s) or guardian(s) } \\
\text { Family other } \\
\text { Other (please specify }\end{array}$ \\
\hline $\begin{array}{l}\text { Did you transfer from another campus/institution to } \\
\text { this school? }\end{array}$ & $\begin{array}{l}\text { Yes } \\
\text { No }\end{array}$ \\
\hline
\end{tabular}




\begin{tabular}{|c|c|}
\hline What is your current GPA? & Free Response \\
\hline $\begin{array}{l}\text { Please indicate your level of involvement in } \\
\text { organized extra-curricular activities (e.g., sports, } \\
\text { clubs, student government, etc.): }\end{array}$ & $\begin{array}{l}\text { None } \\
\text { Occasional participation } \\
\text { One regularly attended activity } \\
\text { Two regularly attended activities } \\
\text { Three or more regularly attended } \\
\text { activities }\end{array}$ \\
\hline $\begin{array}{l}\text { Please estimate the number of hours per week you } \\
\text { are actively involved in organized extracurricular } \\
\text { activities (e.g., sports, clubs, student government, } \\
\text { etc.) }\end{array}$ & Free Response \\
\hline $\begin{array}{l}\text { Do you participate on an athletic team that competes } \\
\text { with other colleges or universities? }\end{array}$ & $\begin{array}{l}\text { Yes } \\
\text { No }\end{array}$ \\
\hline Are you a member of ROTC? & $\begin{array}{l}\text { Yes } \\
\text { No }\end{array}$ \\
\hline $\begin{array}{l}\text { Have you ever served in any branch of the US } \\
\text { military (active duty, veteran, National Guard or } \\
\text { reserves)? }\end{array}$ & $\begin{array}{l}\text { Yes } \\
\text { No }\end{array}$ \\
\hline $\begin{array}{l}\text { Did your military experiences include any traumatic } \\
\text { or highly stressful experiences which continue to } \\
\text { bother you? }\end{array}$ & $\begin{array}{l}\text { Yes } \\
\text { No }\end{array}$ \\
\hline If yes, please describe: & Free Response \\
\hline $\begin{array}{l}\text { What is the average number of hours you work per } \\
\text { week during the school year (paid employment } \\
\text { only)? }\end{array}$ & Free Response \\
\hline $\begin{array}{l}\text { Are you the first generation in your family to attend } \\
\text { college? }\end{array}$ & $\begin{array}{l}\text { Yes } \\
\text { No }\end{array}$ \\
\hline $\begin{array}{l}\text { How would you describe your financial situation } \\
\text { right now: }\end{array}$ & $\begin{array}{l}\text { Always stressful } \\
\text { Often stressful } \\
\text { Sometimes stressful } \\
\text { Rarely stressful } \\
\text { Never stressful }\end{array}$ \\
\hline $\begin{array}{l}\text { How would you describe your financial situation } \\
\text { while growing up: }\end{array}$ & $\begin{array}{l}\text { Always stressful } \\
\text { Often stressful } \\
\text { Sometimes stressful } \\
\text { Rarely stressful } \\
\text { Never stressful }\end{array}$ \\
\hline
\end{tabular}




\section{APPENDIX C: WORKING MEMORY MODEL}

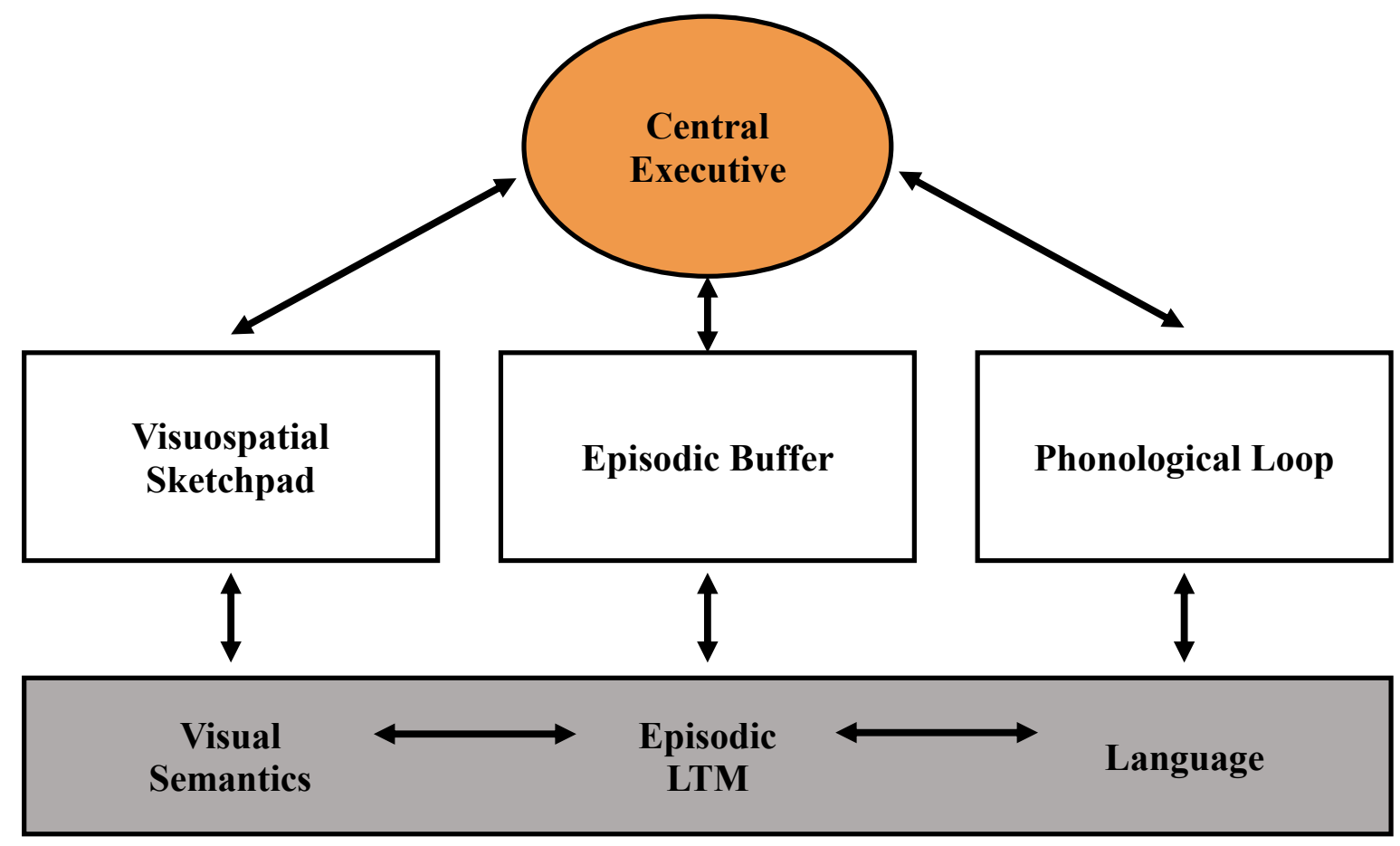

(Baddley \& Hitch, 1974) 


\section{CURRICULUM VITAE}

\section{EDUCATION}

West Virginia University | Morgantown, WV

Anticipated August 2019

Doctor of Philosophy in Counseling Psychology, APA Accredited Program

Dissertation: "Efficacy of Cognitive Training Intervention with Coaching Component on the Attention and Academic Achievement of College Students"

Clemson University | Clemson, SC

May 2010

Master of Education in Counselor Education

Mercer University | Macon, GA

May 2008

Bachelor of Arts in Psychology, Minor in Criminal Justice

Senior Class President

\section{COUNSELING AND ASSESSMENT EXPERIENCES}

\section{Predoctoral Intern}

August 2018 - Present

Counseling and Testing Center | University of Idaho

Supervisor: Martha Kitzrow, Ph.D.

- Psychotherapy: Engage in brief individual therapy with 15 clients weekly. Cofacilitate group therapy. Administer clinically relevant assessment protocols. Facilitate appropriate referrals and continuity of care. Complete all progress notes and associated paperwork in a timely manner.

- Intakes: Responsible for 4 weekly intake appointments and weekly disposition meetings. Communicate all treatment recommendations and referrals to clients and complete associated paperwork within 48 hours.

- Testing: Complete 2 comprehensive psychological examinations for LD/ADHD each semester. Assess multiple areas including cognitive functioning, achievement, memory and learning, executive functioning, attention, and personality. Conduct clinical intake prior to assessments and provide feedback on results.

- Crisis and Consultation: Aid in weekly walk-in crisis shift and provide consultations for students, parents, university staff, and community members. Attend weekly consultation meetings with the psychiatric staff. Conduct extended risk assessment over 3 meetings with clients who are identified as students of concern.

- Supervision and Training: Actively participate in weekly supervision meetings and seminars including individual supervision (2 hours), group supervision (2 hours), and supervision of supervision (1 hour). Supervise doctoral-level practicum student for 1 hour weekly. Participate on center training committee, review training policies, and propose changes for the upcoming year.

- Outreach: Facilitate didactic and interactive outreach programming throughout the semester on a range of topics including trauma-informed care, alcohol use, anxiety, depression, and other mood disorders. 
Therapy Graduate Assistant

May 2017 - May 2018

Carruth Center for Psychological and Psychiatric Services | West Virginia University Training Director: Shane Chaplin, Ph.D.

- Provided 10-15 hours weekly of individual counseling for undergraduate and graduate students

- Performed detailed clinical interviews prior to treatment and appropriate client referrals following the intake

- Conducted a weekly alcohol and marijuana skills-based group for mandated students

- Facilitated electroencephalogram (EEG) neurofeedback for students

- Participated in weekly case conference

- Engaged in 2 hours of individual supervision weekly

\section{Therapist}

August 2016 - May 2017

United Summit Center | Clarksburg, WV

Supervisor: Dennis Kojsza, PhD

- Provided individual counseling for 6-8 clients weekly across a range of presenting concerns

- Conducted court-mandated therapy and assessment for custody evaluations and parental fitness

- Conducted 1-2 psychological evaluations monthly for clients utilizing a battery of assessments

- Wrote weekly integrated reports using data from psychological assessments

- Consulted with case-management staff about appropriate treatment plans

- Tracked billing for psychological services rendered during the day

Assessment Graduate Assistant

August 2015 - May 2017

Carruth Center for Psychological and Psychiatric Services | West Virginia University Supervisor: Daniel Long, Ph.D.

- Conducted 100 MindFit Clinic intakes annually to assess possible etiologies of client's attentional and learning difficulties

- Created individualized treatment plans, performed clinical interviews, and offered appropriate referrals

- Provided various non-pharmacological interventions including cognitive training and neurofeedback

- Participated in weekly case conference and individual supervision

\section{GROUP THERAPY}

- Dialectical Behavioral Therapy (DBT) Skills Group (Spring 2019)

- Substance Abuse Psychoeducation Group for mandated clients (Fall 2018)

- Social Anxiety Group (Spring 2018)

- Substance Abuse Psychoeducation Group for mandated clients (Fall 2017) 


\section{COGNITIVE AND ACHIEVEMENT ASSESSMENTS}

- Wechsler Adult Intelligence Scale (WAIS-IV)

- Wechsler Individual Achievement Test (WIAT-III)

- Wechsler Memory Scale (WMS-IV)

- California Verbal Learning Test (CLVT-3)

- Woodcock-Johnson IV Tests of Cognitive Abilities (WJ-IV-COG)

- Woodcock-Johnson IV Tests of Achievement (WJ-IV-ACH)

- Delis-Kaplan Executive Functioning System (D-KEFS)

- Integrated Visual and Auditory Test (IVA)

\section{PERSONALITY ASSESSMENTS}

- Minnesota Multiphasic Personality Inventory (MMPI-2)

- Minnesota Multiphasic Personality Inventory Restructured Form (MMPI-2-RF)

- Personality Assessment Inventory (PAI)

\section{PROJECTIVE MEASURES}

- House-Tree-Person Test (HTP)

\section{SELF-REPORT MEASURES}

- Brown Attention-Deficit Disorders Scales

- Beck Depression Inventory (BDI)

- Beck Anxiety Inventory (BAI)

- Behavioral Health Questionnaire (BHQ)

- Counseling Center Assessment of Psychological Sypmtoms (CCAPS)

- Alcohol Use Disorders Identification Test (AUDIT)

\section{PROFESSIONAL EXPERIENCES}

Assistant Director of Scholarships

October 2012 - May 2014

Watson-Brown Foundation | Thomson, GA

- Cultivated relationships with high school students, counselors, college/university students and alumni

- Managed the selection process for 1,500+ scholarship applicants and assisted 800+ current recipients

- Offered presentations on test preparation to local schools, guidance counselors, and students

- Served as a panelist for private foundation professionals, facilitating discussion during monthly webinars 
James M. Hull College of Business | Augusta State University

- Advised 450 students majoring in Accounting, Finance, and Management Information Systems

- Coordinated week-long networking events for students and employers

- Recruited potential business students from area high schools

- Analyzed student data to create new initiatives for the college

- Reduced the number of students on probation through engaged student advising

Graduate Assistant

College of Architecture, Arts, \& Humanities | Clemson University

May 2008 - May 2010

- Built rapport with 120 undergraduate students during advising appointments

- Conducted Academic Quotient study with the Office of New Student and Sophomore Programs

- Presented to 800 incoming freshmen and transfer students during summer orientation about university policies, general education requirement, AP and IB credit, and placement testing

- Coordinated annual phone-a-thon for the College of Architecture, Arts, and Humanities

Graduate Intern

Service Quality Unit | University of Sheffield, United Kingdom

May 2009 - June 2009

- Initiated survey assessing student complaints and academic appeals

- Generated a database of incidents compiled from each academic department to forecast the number of incidents in future years

- Assessed the number and severity of student complaints and academic appeals at the graduate level

- Offered findings of assessment survey to key members of the Student Services Department

Graduate Intern

August 2009 - December 2009

Office of Community and Ethical Standards | Clemson University

- Mentored a student judicial board of 5 students and oversaw 20 student conduct hearings

- Investigated and adjudicated instances of alleged student misconduct in individual hearings

- Managed student conduct hearings using the Maxient database

Practicum Student

January 2009 - May 2010

Office of the Vice President of Student Affairs |Clemson University

- Analyzed a national assessment tool (PACS) to help administrators identify strengths and opportunities related to the mission and vision of the university

- Created an assessment tool for the Clemson University Police Department assessing driver safety, overall satisfaction, and efficiency of the shuttle service 
Committee Member

Sophomore Year Task Force Committee | Clemson University

January 2009 - May 2010

- Formulated strategies to increase student engagement and retention within living learning communities

- Coordinated new initiatives for sophomores to increase academic engagement on campus

\section{PROFESSIONAL PRESENTATIONS}

Gingles, R.M., \& Foster, T.C. (August 2015). Law Enforcement Officer Ambushes: The Psychology of Officers and Offenders ("The Psychology of Police Officers in Ambushes"). Symposium at the American Psychological Association National Convention, Toronto, ON.

Cognitive Training as a Treatment for ADHD in College Students (April 2016). Poster session at Student Research Fair at West Virginia University, Morgantown, WV.

Shadow Majoring (September 2011). Presentation at the NACADA Drive-in Conference, Decatur, GA.

Academic Infraction Assessment (May 2009). Presentation at Sheffield University, Sheffield, England.

Shuttle Assessment (January 2009). Presentation at Clemson University, Clemson, SC.

\section{OUTREACH PRESENTATIONS}

Mental Health Challenges in College Students (January 2019). Presentation at the University of Idaho, Moscow, ID.

Stress and Anxiety (2017). Workshop series at West Virginia University, Morgantown, WV.

College Scholarship Applications (March 2014). Workshop at Georgia College and State University, Milledgeville, GA.

The Hull Advantage (April 2012). Workshop series at Augusta State University, Augusta, GA.

College of Business Myths (March 2011). Workshop series at Augusta State University, Augusta, GA.

Alternative Majors (November 2009). Workshop series at Clemson University, Clemson, SC. 
Profile of Majors (October 2009). Workshop series at Clemson University, Clemson, SC.

\section{RESEARCH}

Graduate Researcher

August 2014 - August 2015

Law Enforcement Officer Killed and Assaulted Program | West Virginia University

- Conducted qualitative inquiry on police officer ambushes in collaboration with the Federal Bureau of Investigation (FBI) through the LEOKA program

- Co-presented findings at 2015 APA National Convention in Toronto, Canada

\section{LEADERSHIP AND PROFESSIONAL INVOLVEMENTS}

Advisor, Student Health Advisory Board

West Virginia University

Campus Representative,

Association of Military Psychology

West Virginia University

Treasurer, Student Personnel Association

Clemson University

Intern, District Attorney's Office

Toomb's Judicial Circuit

Undergraduate Honor Council Justice

Mercer University
September 2015 - May 2016

August 2014 - May 2016

August 2009 - May 2010

August 2007 - December 2007

February 2007 - May 2008

\section{AWARDS AND HONORS}

Chi Sigma Alpha, Student Affairs Academic and Professional Honor Society | 2009

Phi Eta Sigma National Honor Society, Inc. | 2005

Watson Brown Scholarship Recipient | 2004-2008

Eagle Scout | 2004

\section{PROFESSIONAL ORGANIZATIONS}

Student Affiliate, American Psychological Association

Student Affiliate, Society of Counseling Psychology
August 2014 - Present

August 2014 - Present 